\title{
Improved Estimation of the Specific Attenuation and Backscatter Differential Phase over Short Rain Paths
}

\author{
RicARdo ReINOSO-Rondinel, CHRISTINE UnAL, AND HERMAN RuSSCHENBERG \\ Faculty of Civil Engineering and Geosciences, Delft University of Technology, Delft, Netherlands
}

(Manuscript received 19 December 2017, in final form 25 September 2018)

\begin{abstract}
In radar polarimetry, the differential phase $\Psi_{\mathrm{DP}}$ consists of the propagation differential phase $\Phi_{\mathrm{DP}}$ and the backscatter differential phase $\delta_{\mathrm{hv}}$. While $\Phi_{\mathrm{DP}}$ is commonly used for attenuation correction (i.e., estimation of the specific attenuation $A$ and specific differential phase $K_{\mathrm{DP}}$ ), recent studies have demonstrated that $\delta_{\mathrm{hv}}$ can provide information concerning the dominant size of raindrops. However, the estimation of $\Phi_{\mathrm{DP}}$ and $\delta_{\mathrm{hv}}$ is not straightforward given their coupled nature and the noisy behavior of $\Psi_{\mathrm{DP}}$, especially over short paths. In this work, the impacts of estimating $\Phi_{\mathrm{DP}}$ on the estimation of $A$ over short paths, using the extended version of the ZPHI method, are examined. Special attention is given to the optimization of the parameter $\alpha$ that connects $K_{\mathrm{DP}}$ and $A$. In addition, an improved technique is proposed to compute $\delta_{\mathrm{hv}}$ from $\Psi_{\mathrm{DP}}$ and $\Phi_{\mathrm{DP}}$ in rain. For these purposes, diverse storm events observed by a polarimetric X-band radar in the Netherlands are used. Statistical analysis based on the minimum errors associated with the optimization of $\alpha$ and the consistency between $K_{\mathrm{DP}}$ and $A$ showed that more accurate and stable $\alpha$ and $A$ are obtained if $\Phi_{\mathrm{DP}}$ is estimated at range resolution, which is not possible by conventional range filtering techniques. Accurate $\delta_{\mathrm{hv}}$ estimates were able to depict the spatial variability of dominant raindrop size in the observed storms. By following the presented study, the ZPHI method and its variations can be employed without the need for considering long paths, leading to localized and accurate estimation of $A$ and $\delta_{\mathrm{hv}}$.
\end{abstract}

\section{Introduction}

Conventional S- and C-band weather radars have been used for several decades to monitor the evolution of precipitation. In recent years the technology of those conventional radars has been upgraded to polarimetric technology in order to further improve weather radar measurements (Doviak et al. 2000). Severe weather can produce rapid and localized surface damage associated with, for example, heavy rain and tornadoes. In this context, a network of small polarimetric X-band weather radars may be suitable to obtain observations of fastdeveloping storms at close range and at resolutions higher than those from conventional radars (McLaughlin et al. 2009; Chandrasekar et al. 2018).

One of the advantages of polarimetric radars is given by the measurements of differential phase between the horizontally and vertically polarized signals caused by the delay of one with respect to the other as both signals propagate through hydrometeors. In this way, the

Corresponding author: Ricardo Reinoso-Rondinel, r.reinosorondinel@ tudelft.nl differential phase $\Psi_{\mathrm{DP}}\left(^{\circ}\right)$ is independent of attenuation, miscalibration, and partial beam blockage (PBB) effects (Doviak and Zrnić 1993). However, $\Psi_{\mathrm{DP}}$ measurements can include phase shifts in the backward direction as a result of Mie scattering, the so-called backscatter differential phase $\delta_{\mathrm{hv}}\left({ }^{\circ}\right)$, and random fluctuations $\varepsilon\left(^{\circ}\right)$ on the order of few degrees. In general, a $\Psi_{\mathrm{DP}}$ range profile is modeled as

$$
\Psi_{\mathrm{DP}}(r)=\Phi_{\mathrm{DP}}(r)+\delta_{\mathrm{hv}}(r)+\varepsilon,
$$

where $\Phi_{\mathrm{DP}}(r)\left(^{\circ}\right)$ represents the differential phase in the forward direction and $r(\mathrm{~km})$ indicates the distance from the radar. Two useful variables that can be estimated from $\Phi_{\mathrm{DP}}$ are the specific differential phase $K_{\mathrm{DP}}\left({ }^{\circ} \mathrm{km}^{-1}\right)$ and the specific attenuation $A\left(\mathrm{~dB} \mathrm{~km}^{-1}\right)$, which are commonly used for the estimation of rainfall rate and attenuation correction (Bringi and Chandrasekar 2001).

The traditional method to estimate $K_{\mathrm{DP}}$ (or $\Phi_{\mathrm{DP}}$ ) from $\Psi_{\mathrm{DP}}$ when $\delta_{\mathrm{hv}}$ is significant is given by Hubbert and Bringi (1995), and several attempts have been proposed to improve $K_{\mathrm{DP}}$ estimates at X-band frequencies (Wang and Chandrasekar 2009; Giangrande et al. 2013; Schneebeli et al. 2014; Huang et al. 2017). The specific 
differential phase $K_{\mathrm{DP}}$ has been used to correct measurements of reflectivity $Z(\mathrm{~dB} Z)$ affected by radar calibration and PBB (Giangrande and Ryzhkov 2005). In addition, $K_{\mathrm{DP}}$ has led to improved estimation of rainfall rate, mostly in heavy rain or mix rain, because of its quasi-linear relation to liquid water content ( $\mathrm{Lim}$ et al. 2013). Although radar measurements seem to benefit from using $K_{\mathrm{DP}}$, comprehensive research on $K_{\mathrm{DP}}$ is still needed because it is a challenge to provide accurate $K_{\mathrm{DP}}$ from noisy measurements of $\Psi_{\mathrm{DP}}$.

Existing methods to estimate $A$ in rain assume that $A=\alpha K_{\mathrm{DP}}$, where $\alpha$ is a constant for a given frequency (Bringi et al. 1990). Testud et al. (2000) also used the relation between $A$ and $K_{\mathrm{DP}}$ in their rain profiling ZPHI technique, to express $A$ in terms of the difference of $\Phi_{\mathrm{DP}}$ and measurements of $Z$, avoiding $K_{\mathrm{DP}}$ calculation. However, it is known that $\alpha$ is sensitive to temperature, drop size distribution (DSD), and drop size variabilities; therefore, Bringi et al. (2001) extended the ZPHI technique to avoid a priori value for $\alpha$. These methods have been adapted to address attenuation problems at X-band frequencies (Matrosov et al. 2002; Park et al. 2005a; Gorgucci et al. 2006; Lim and Chandrasekar 2016). Moreover, Ryzhkov et al. (2014), Wang et al. (2014), and Diederich et al. (2015) modified the extended ZPHI method to improve rainfall-rate estimation and to demonstrate that $A$ can be used to reduce issues related to radar calibration and PBB. Despite these promising benefits, the potential of using $A$ might be limited depending on the approach to obtain $\Phi_{\mathrm{DP}}$ and $\alpha$ (Bringi et al. 2001; Ryzhkov and Zrnić 2005).

In contrast to $K_{\mathrm{DP}}$ and $A$, limited research has been conducted on the applications of $\delta_{\mathrm{hv}}$. For example, $\delta_{\mathrm{hv}}$ can be a suitable candidate to mitigate uncertainties related to the differential reflectivity $Z_{\mathrm{DR}}(\mathrm{dB})$ because $\delta_{\mathrm{hv}}$ and $Z_{\mathrm{DR}}$ offer a correlated behavior (Scarchilli et al. 1993; Testud et al. 2000) and because $\delta_{\text {hv }}$ is independent of attenuation and radar calibration; see Eq. (1). These aspects of $\delta_{\mathrm{hv}}$ could be useful to establish relations between $\delta_{\mathrm{hv}}$ and the median drop diameter $D_{0}(\mathrm{~mm})$ (Trömel et al. 2013) because $D_{0}$ is often expressed in terms of $Z_{\mathrm{DR}}$ (Matrosov et al. 2005; Kim et al. 2010). Moreover, Otto and Russchenberg (2010) included $\delta_{\mathrm{hv}}$ estimates to retrieve DSD parameters. Hubbert and Bringi (1995), Otto and Russchenberg (2011), and Trömel et al. (2013) estimated $\delta_{\mathrm{hv}}$ by subtracting $\Phi_{\mathrm{DP}}$ from $\Psi_{\mathrm{DP}}$, while Schneebeli and Berne (2012) included a Kalman filter approach. The effectiveness of estimating $\delta_{\text {hv }}$ at high resolution is rather complicated because of the cumulative and noisy nature of $\Psi_{\mathrm{DP}}$ and possible remaining fluctuations on $\Phi_{\mathrm{DP}}$.

The purpose of this work is to 1) explore the role and impact of estimated $\Phi_{\mathrm{DP}}$ profiles on the performance of the extended ZPHI method at X-band frequencies to improve estimates of $\alpha$ and $A$ over short paths and 2) develop a technique to compute $\delta_{\mathrm{hv}}$ in rain while keeping the spatial variability of drop sizes. For such purpose, two $K_{\mathrm{DP}}$ (or $\Phi_{\mathrm{DP}}$ ) methods, by Hubbert and Bringi (1995) and Reinoso-Rondinel et al. (2018), are reviewed in section 2 as well as three attenuation correction approaches, by Bringi et al. (1990), Testud et al. (2000), and Bringi et al. (2001). In addition, the $\delta_{\mathrm{hv}}$ algorithm is introduced, which integrates estimates of $K_{\mathrm{DP}}$ and $A$. In section 3 , the performances of the attenuation correction methods that assume a constant $\alpha$ are compared using four storm events. This comparison is extended in section 4 to examine the selection of $\alpha$ profile by profile and its impact on $A$ and $Z$. In section 5, the $\delta_{\text {hv }}$ technique is evaluated. Section 6 focuses on the statistics of $\alpha, A, Z$, and $\delta_{\text {hv }}$ to conduct further assessments of the presented methods. Finally, section 7 draws conclusions of this article.

\section{Estimation techniques for $\Psi_{\mathrm{DP}}$-based variables}

\section{a. Estimation of $K_{\mathrm{DP}}$}

In the conventional technique given by Hubbert and Bringi (1995), a low-pass filter is designed such that gateto-gate fluctuations at scales of the range resolution $\Delta r$ $(\mathrm{km})$ are filtered from a $\Psi_{\mathrm{DP}}(r)$ profile. Fluctuations at range scales larger than $\Delta r$ (i.e., $\delta_{\mathrm{hv}}$ "bumps") are removed by applying the same filter multiple times to new generated $\Psi_{\mathrm{DP}}^{g}$ profiles by combining a previous filtered and original $\Psi_{\text {DP }}$ profile. In this manner the corresponding $\Phi_{\mathrm{DP}}$ profile is obtained and $K_{\mathrm{DP}}$ is given by taking a range derivative of $\Phi_{\mathrm{DP}}$. For the generation of $\Psi_{\mathrm{DP}}^{g}$, a predetermined threshold $\tau\left(^{\circ}\right)$ is required, which is on the order of 1-2 times the standard deviation of $\Psi_{\mathrm{DP}}$, hereafter $\sigma_{P}\left({ }^{\circ}\right)$. One of the limitations of this technique is that accurate estimates of $\Phi_{\mathrm{DP}}$ and $K_{\mathrm{DP}}$ at $\Delta r$ scales are hardly achieved (Grazioli et al. 2014).

An adaptive approach that estimates $K_{\mathrm{DP}}$ at high spatial resolution while controlling its standard deviation $\sigma_{K}\left({ }^{\circ} \mathrm{km}^{-1}\right)$ is given by Reinoso-Rondinel et al. (2018). For notation purposes, the difference of a radar variable $V$ over a given pathlength is expressed as $\Delta V$. Besides $\Psi_{\mathrm{DP}}$, attenuation-corrected $Z$ and $Z_{\mathrm{DR}}$ profiles are also required, as well as a predefined pathlength interval $\left[L_{\min } ; L_{\max }\right](\mathrm{km})$. For gate $i$, located at range $r_{i}$, a set of $\sigma_{K}$ samples are obtained from $\left[L_{\min } ; L_{\max }\right]$ using a theoretical expression of $\sigma_{K}$. The pathlength that minimizes the $\sigma_{K}$ set is selected and denoted as $L(i)$. Assuming the correlated behavior between $Z_{\mathrm{DR}}$ and $\delta_{\mathrm{hv}}$, $\Delta \Psi_{\mathrm{DP}}$ samples in the range $\left[r_{i}-L(i) ; r_{i}+L(i)\right]$ that do not satisfy the condition $\left|\Delta Z_{\mathrm{DR}}\right|<\sigma_{Z_{\mathrm{DR}}}$ are filtered to avoid contamination from $\Delta \delta_{\mathrm{hv}}$. The standard deviation 


\section{a) Specific differential phase methods}

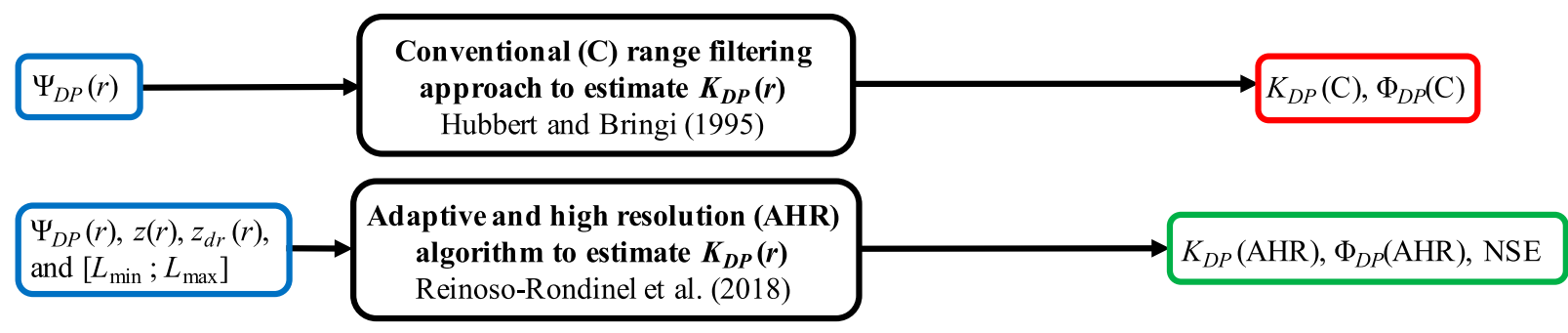

\section{b) Specific attenuation methods}
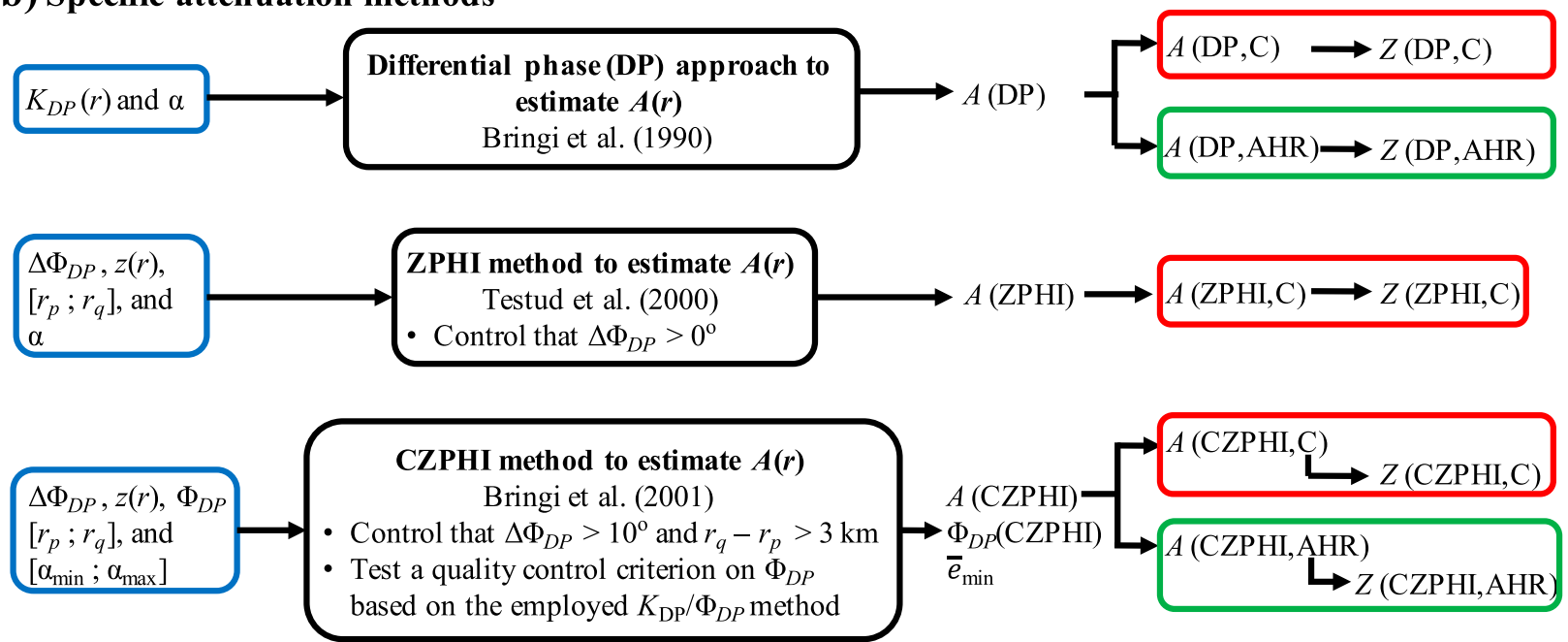

FIG. 1. Methods associated with the estimation of (a) $K_{\mathrm{DP}}$ and (b) $A$. The outputs related to the conventional $K_{\mathrm{DP}}$ technique are indicated with red, while the outputs related to the adaptive high-resolution approach are indicated with green.

of the $Z_{\mathrm{DR}}$ profile is denoted as $\sigma_{Z_{\mathrm{DR}}}$. The spatial variability of $\Psi_{\mathrm{DP}}$ at $\Delta r$ scales is captured by downscaling each remaining $\Delta \Psi_{\mathrm{DP}}$ sample from $L(i)$ to $\Delta r$ scale. A downscaling parameter $w(i) \in[0,1]$ is derived from $Z$ and $Z_{\mathrm{DR}}$ in the same interval $\left[r_{i}-L(i) ; r_{i}+L(i)\right]$, and $K_{\mathrm{DP}}(i)$ is estimated as

$K_{\mathrm{DP}}(i)=\frac{1}{M} \sum_{j=1}^{M} \frac{\Delta \Psi_{\mathrm{DP}}^{(j)} w^{(j)}(i)}{2 \Delta r}, \quad$ with $\quad j=1,2, \ldots, M$,

where $M$ represents the number of $\Delta \Psi_{\mathrm{DP}}$ samples with negligible $\Delta \delta_{\mathrm{hv}}$. The actual $\sigma_{K}(i)$ is calculated using the terms inside the sum operation in Eq. (2). The $K_{\mathrm{DP}}$ and $\sigma_{K}$ profiles are obtained by repeating the same procedure over the remaining gates, while the corresponding $\Phi_{\mathrm{DP}}$ profile is calculated by simply integrating $K_{\mathrm{DP}}$ in range. In addition, a profile of the normalized standard error (NSE) of $K_{\mathrm{DP}}$ is given by the ratio between actual $\sigma_{K}$ and $K_{\mathrm{DP}}$. This approach was demonstrated for rain particles at $\mathrm{X}$-band frequencies, and therefore any undetected $Z$ and $Z_{\mathrm{DR}}$ echoes from hydrometeors other than rain can lead to inaccurate $K_{\mathrm{DP}}$ estimates. The two $K_{\text {DP }}$ methods will be referred to as the conventional (C) and the adaptive high-resolution (AHR) approaches, respectively. A diagram is presented in Fig. 1 to briefly indicate the inputs and outputs of each method.

\section{b. Estimation of $A$}

For attenuation correction purposes, $Z$ and $Z_{\mathrm{DR}}$ profiles are represented as $Z(r)=z(r)+\operatorname{PIA}(r)$ and $Z_{\mathrm{DR}}(r)=z_{\mathrm{dr}}(r)+\mathrm{PIA}_{\mathrm{DP}}(r)$, respectively, where $z(\mathrm{~dB} Z)$ and $z_{\mathrm{dr}}(\mathrm{dB})$ represent the attenuated reflectivity and the attenuated differential reflectivity, respectively; and $\operatorname{PIA}(r)(\mathrm{dB})$ indicates the two-way path-integrated attenuation in reflectivity and $\operatorname{PIA}_{\mathrm{DP}}(r)(\mathrm{dB})$ in differential reflectivity.

Bringi et al. (1990) introduced the differential phase (DP) approach such that $A(r)=\alpha K_{\mathrm{DP}}(r)$ and $\operatorname{PIA}(r)=\alpha \Phi_{\mathrm{DP}}(r)$, where $\alpha\left[\mathrm{dB}\left({ }^{\circ}\right)^{-1}\right]$ is assumed to be a constant coefficient. Gorgucci and Chandrasekar (2005) studied the accuracy of this method using simulated radar variables at $\mathrm{X}$-band frequencies and showed that 
estimates of $A$ are very sensitive to inaccurate estimates of $K_{\mathrm{DP}}$, while estimates of PIA lead to $Z$ values associated with only a slight degradation of the average error for attenuation correction, $\pm 1.5 \mathrm{~dB}$.

To improve the DP method, Testud et al. (2000) introduced the ZPHI method that estimates $A(r)$ in a path interval $\left[r_{p} ; r_{q}\right]$, where $r_{q}>r_{p}$. First, $A(r)$ is expressed as a function of two known variables, $z(r)$ and $z\left(r_{q}\right)$, and one unknown, $A\left(r_{q}\right)$. Then, $A\left(r_{q}\right)$ is obtained using $z\left(r_{q}\right)$ and the empirical relation $\Delta \mathrm{PIA}=\alpha \Delta \Phi_{\mathrm{DP}}$, where $\Delta \mathrm{PIA}=$ $\operatorname{PIA}\left(r_{q}\right)-\operatorname{PIA}\left(r_{p}\right)$ and $\Delta \Phi_{\mathrm{DP}}=\Phi_{\mathrm{DP}}\left(r_{q}\right)-\Phi_{\mathrm{DP}}\left(r_{p}\right)$. In this way, $A(r)$ is estimated at $\Delta r$ scales, reducing errors related to $K_{\mathrm{DP}}(r)$. Although $\left[r_{p} ; r_{q}\right]$ can be freely selected; $\Delta \Phi_{\mathrm{DP}}$ could be inaccurate at short path intervals and/or be contaminated by $\delta_{\mathrm{hv}}\left(r_{p}\right)$ and $\delta_{\mathrm{hv}}\left(r_{q}\right)$. In addition, if $z(r)$ includes localized observations of hail or mixtures of rain and hail in $\left[r_{p} ; r_{q}\right]$, then $A(r)$ might be biased over the entire path interval.

Using a constant $\alpha$ may lead to limited approximations of $A(r)$ and PIA $(r)$ because $\alpha$ is sensitive to DSD, drop shape, and temperature variabilities (Jameson 1992). To take into account the sensitivity of $\alpha$, Bringi et al. (2001) extended the ZPHI method to search for optimal $\alpha$ values at C-band frequencies, called the CZPHI method. An initial value for $\alpha$ is selected from a predefined interval $\left[\alpha_{\min } ; \alpha_{\max }\right]$, and $A(r)$ is estimated according to the ZPHI method. The estimated $A(r)$ is integrated over $\left[r_{p} ; r_{q}\right]$ to build a differential phase profile denoted as $\Phi_{\mathrm{DP}}(r, \alpha)$. Repeating this procedure for the remaining values of $\alpha$, the optimal $\alpha$ is the one that minimizes the error $E\left(^{\circ}\right)$ given by

$E=\sum_{i=p}^{q}\left|\Phi_{\mathrm{DP}}\left(r_{i}, \alpha\right)-\Phi_{\mathrm{DP}}\left(r_{i}\right)\right|, \quad$ with $\quad i=p, \ldots, q$.

Note that the optimization process requires the estimation of $\Phi_{\mathrm{DP}}$, which implies the need for a proper way to filter noise and $\delta_{\mathrm{hv}}$ components from $\Psi_{\mathrm{DP}}$ while maintaining its spatial variability. However, meeting such requirements is not straightforward; therefore, the reliability of an "optimal" $\alpha$ to estimate $A$ and PIA depends on the performance of the chosen approach to estimate $\Phi_{\mathrm{DP}}$. The inputs and outputs associated with the three presented attenuation correction methods are summarized in Fig. 1.

To determine PIA $_{\mathrm{DP}}(r)$, integrate the specific differential attenuation $A_{\mathrm{DP}}(r)\left(\mathrm{dB} \mathrm{km}^{-1}\right)$ that is given by $A_{\mathrm{DP}}=\gamma A$. The DP and ZPHI methods assume $\gamma$ to be constant, whereas the CZPHI technique searches for an optimal $\gamma$, addressing its sensitivity to DSD variability (i.e., rain type). However, such sensitivity of $\gamma$ is less at $\mathrm{X}$-band frequencies than at $\mathrm{C}$ - and $\mathrm{S}$-band frequencies (Ryzhkov et al. 2014). In this work, $A_{\mathrm{DP}}$ will be given by
$A_{\mathrm{DP}}=\gamma A(\mathrm{CZPHI})$, where $A(\mathrm{CZPHI})$ represents the specific attenuation determined by the CZPHI approach and $\gamma$ is assumed a constant.

Representative values for $\alpha$ and $\gamma$ at X-band frequencies can be given by the mean fit of simulated polarimetric relations using a large set of DSDs and different drop shapes and temperatures. For example, Kim et al. (2010) and Ryzhkov et al. (2014) demonstrated that $\alpha$ values vary in the interval $[0.1 ; 0.6] \mathrm{dB}$ $\left({ }^{\circ}\right)^{-1}$, and Otto and Russchenberg (2011) obtained an average value of $0.34 \mathrm{~dB}\left({ }^{\circ}\right)^{-1}$ for $\alpha$ and for $\gamma$ a value of 0.1618 . Similar results were suggested by Testud et al. (2000), $\alpha=0.315 \mathrm{~dB}\left({ }^{\circ}\right)^{-1}$; Kim et al. (2010), $\alpha=0.35 \mathrm{~dB}$ $\left({ }^{\circ}\right)^{-1}$; and Snyder et al. (2010) $\alpha=0.313 \mathrm{~dB}\left({ }^{\circ}\right)^{-1}$; while Ryzhkov et al. (2014) estimated $\gamma$ equal to 0.14 for tropical rain (i.e., low $Z_{\mathrm{DR}}$ and high $K_{\mathrm{DP}}$ ) and 0.19 for continental rain (i.e., high $Z_{\mathrm{DR}}$ and low $K_{\mathrm{DP}}$ ). It is important to note that other authors have suggested smaller average values for $\alpha$. For example, Bringi and Chandrasekar (2001) simulated polarimetric variables in rain and indicated that $\alpha=0.23 \mathrm{~dB}\left({ }^{\circ}\right)^{-1}$. Matrosov et al. (2014) avoided simulations by using observations resulting from collocated $\mathrm{X}$ - and S-band radars and found $\alpha$ in the range of $0.20-0.31 \mathrm{~dB}\left({ }^{\circ}\right)^{-1}$. Thus, a representative value for $\alpha$ can vary depending on models and assumptions used to simulate polarimetric variables, on the type of observed storms and their geographical locations, and on the accuracy of measurements.

\section{c. Estimation technique for $\delta_{\mathrm{hv}}$}

A $\delta_{\text {hv }}$ approach is presented to identify and separate Mie scattering signatures from noise and random fluctuations embedded in $\Psi_{\mathrm{DP}}$. A flowchart of the $\delta_{\mathrm{hv}}$ algorithm is illustrated in Fig. 2. Three inputs are required: a $2 \mathrm{D} \Psi_{\mathrm{DP}}$ field measured in rain, the corresponding $K_{\mathrm{DP}}$ field obtained from the AHR approach, and the $A$ field estimated by the CZPHI method. Given these inputs, the resulting $\delta_{\mathrm{hv}}$ field is based on the following five steps:

1) Design and apply a filter to smooth strong outliers from a $\Psi_{\mathrm{DP}}$ profile, taking $\Delta r$ into account. Correct each smoothed $\Psi_{\mathrm{DP}}^{\prime}$ profile for system phase offset by subtracting the mean of $\Psi_{\mathrm{DP}}^{\prime}$ over the first $5 \%$ of measured gates.

2) Obtain $\Phi_{\mathrm{DP}}$ by integrating profiles of $A$, if they are associated with a minimum error $E$, otherwise by integrating $K_{\mathrm{DP}}$ profiles. Next, subtract $\Phi_{\mathrm{DP}}$ from $\Psi_{\mathrm{DP}}^{\prime}$, profile by profile, as a first attempt to estimate the corresponding $\delta_{\text {hv }}$ field. The next steps are related to $2 \mathrm{D}$ processing.

3) Remove unusual $\delta_{\text {hv }}$ values larger than $12^{\circ}$ from the $\delta_{\mathrm{hv}}$ field. According to Testud et al. (2000), 


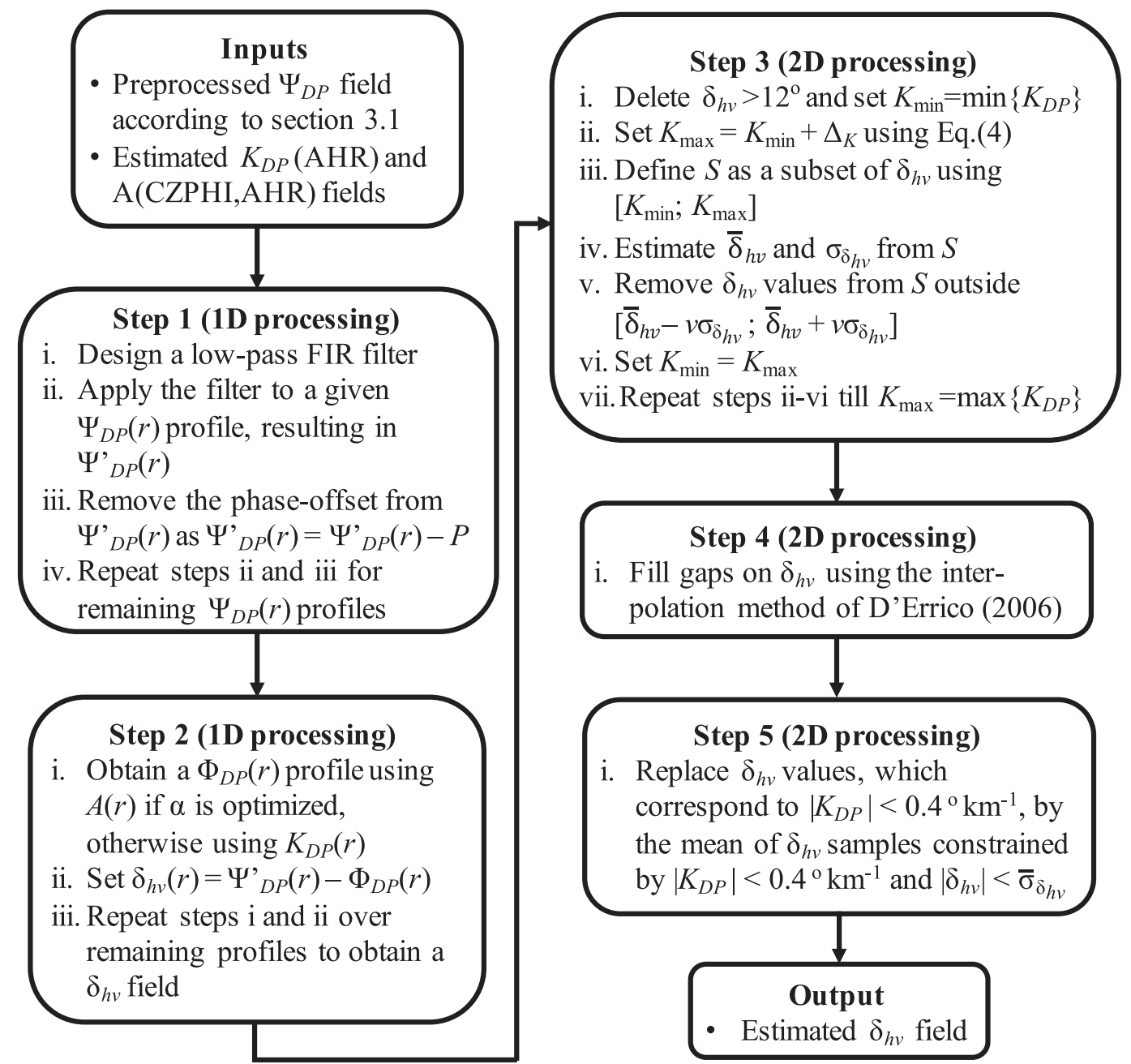

FIG. 2. A flowchart for the estimation of $\delta_{\mathrm{hv}}$. It consists of five steps, where steps 1 and 2 are processed in 1D (i.e., along a PPI radial), while steps 3-5 are processed in 2D (i.e., a complete PPI).

Trömel et al. (2013), and Schneebeli et al. (2014), the simulated $\delta_{\mathrm{hv}}$ values at X-band frequencies rarely reach $12^{\circ}$. The remaining noise in $\delta_{\mathrm{hv}}$ is reduced by assuming that similar values of $\delta_{\mathrm{hv}}$ are collocated with similar values of $K_{\mathrm{DP}}$ as follows. Set $K_{\min }$ as the minimum of $K_{\mathrm{DP}}$ and $K_{\max }$ as $K_{\min }+\Delta_{K}$, where $\Delta_{K}$ $\left({ }^{\circ} \mathrm{km}^{-1}\right)$ is given by Eq. (4). Define $S$ as a set of $\delta_{\mathrm{hv}}$ samples, whose gates are collocated with $K_{\mathrm{DP}}$ values in the interval $\left[K_{\min } ; K_{\max }\right]$. Reject $\delta_{\mathrm{hv}}$ samples from $S$ that are outside the interval $\left[\bar{\delta}_{\mathrm{hv}}-v \sigma_{\delta_{\mathrm{hv}}} ; \bar{\delta}_{\mathrm{hv}}+v \sigma_{\delta_{\mathrm{hv}}}\right]$, where $\bar{\delta}_{\mathrm{hv}}$ and $\sigma_{\delta_{\mathrm{hv}}}$ indicate the arithmetic mean and the standard deviation of the samples in $S$, respectively; $v$ is a predefined threshold in the interval $[1 ; 2]$ and a value of 1 is chosen. This process is iterated by shifting $\left[K_{\min } ; K_{\max }\right]$ toward high values in small steps such that $K_{\min }=K_{\max }$ and $K_{\max }=K_{\min }+\Delta_{K}$ until $K_{\max }$ is equal to the maximum of $K_{\mathrm{DP}}$. To obtain sufficient samples in $S, \Delta_{K}$ is given as

$$
\Delta_{K}=\left\{\begin{array}{rr}
0.2 & K_{\min } \leq 2.5^{\circ} \mathrm{km}^{-1}, \\
0.5 & 2.5^{\circ}<K_{\min }<8^{\circ} \mathrm{km}^{-1}, \\
1.0 & K_{\min } \geq 8^{\circ} \mathrm{km}^{-1},
\end{array}\right.
$$

because high $K_{\mathrm{DP}}$ values are less frequent than small $K_{\mathrm{DP}}$ values (e.g., see the $K_{\mathrm{DP}}$ fields in Figs. 3, 8 , and 11).

4) Apply a 2D interpolation method to fill empty gaps on $\delta_{\mathrm{hv}}$ caused by step 3 . For this task, the inpainting (or image fill-in) algorithm (Bertalmio et al. 2003; Criminisi et al. 2004; Elad et al. 2005) is selected because it is one of the image processing algorithms commonly used to smoothly interpolate 2D images. The essential idea is to formulate a partial differential equation (PDE) for the "hole" (interior unknowns) and to use the perimeter of the hole to obtain boundary values. The solution for the interior 

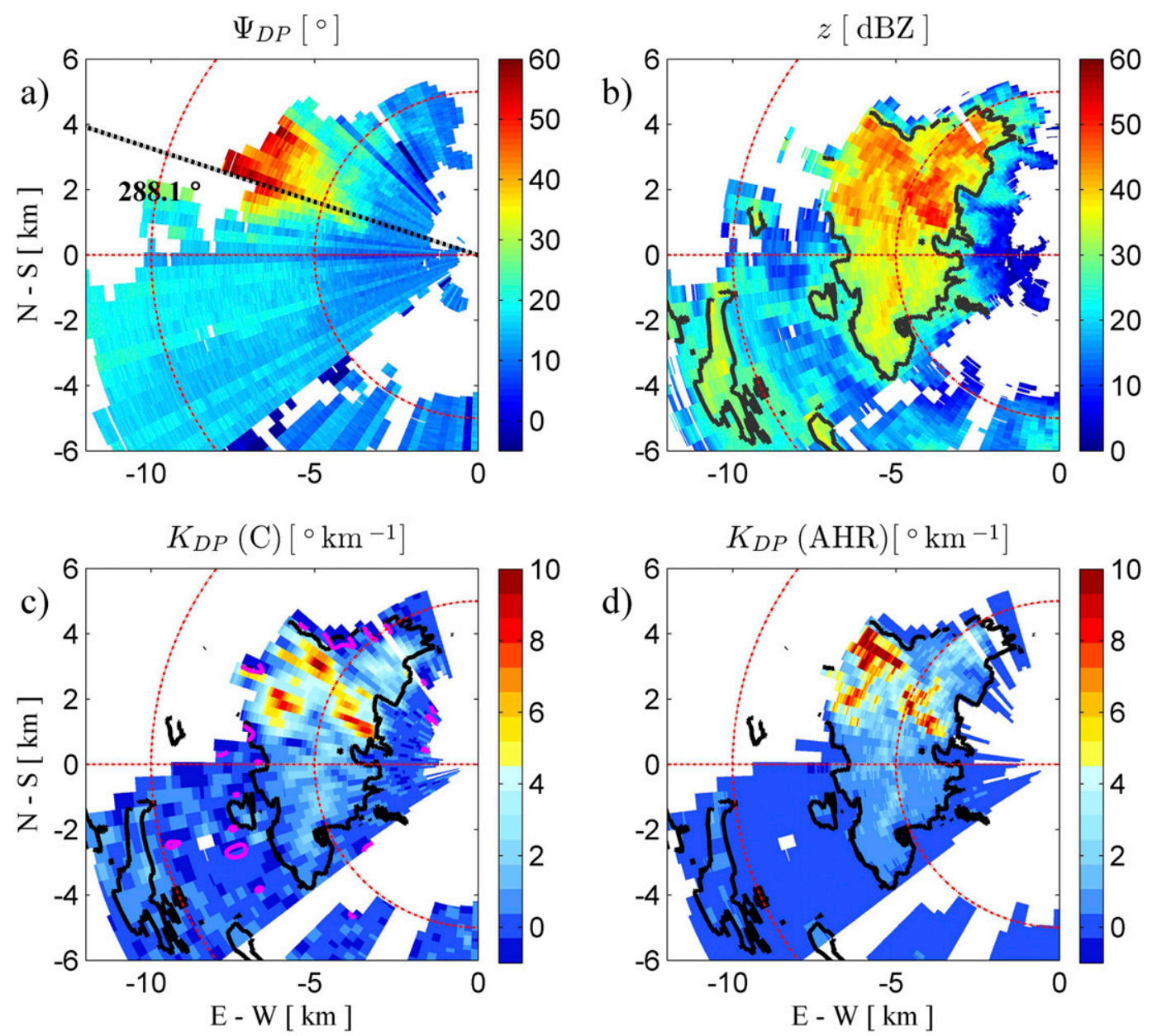

FIG. 3. Observations by IDRA radar at elevation angle of $0.5^{\circ}$ in the NL at 1216 UTC 18 Jun 2011, event E1. Fields of (a) differential phase $\Psi_{\mathrm{DP}}$, (b) $z$, (c) $K_{\mathrm{DP}}(\mathrm{C})$ from the conventional approach, and (d) $K_{\mathrm{DP}}(\mathrm{AHR})$ from the AHR approach. In (b)-(d), attenuation-corrected 30-dBZ levels are indicated by black contour lines; in (c) and (d), $-1^{\circ} \mathrm{km}^{-1}$ levels are indicated by magenta contour lines. The red rings are at $5-\mathrm{km}$ increments.

unknowns involves the discretization of PDEs on the unknowns' points into a system of linear equations. D'Errico (2006) implemented an inpainting code for $2 \mathrm{D}$ arrays that is freely available and used for this step. The code offers multiple methods to formulate a PDE, and the method referred to as the spring method is selected because it provides a reasonable compromise between accuracy and computational time.

5) (optional) To better distinguish storm cells from their background (i.e., for radar displaying purposes), it is recommended to replace areas of $\delta_{\mathrm{hv}}$ that are linked to $\left|K_{\mathrm{DP}}\right|<0.4^{\circ} \mathrm{km}^{-1}$ (i.e., weak rain echoes) by a representative value. This value is chosen as the mean of $\delta_{\mathrm{hv}}$ samples constrained by $\left|K_{\mathrm{DP}}\right|<0.4^{\circ} \mathrm{km}^{-1}$ and $\left|\delta_{\mathrm{hv}}\right|<\bar{\sigma}_{\delta_{\mathrm{hv}}}$, where $\bar{\sigma}_{\delta_{\mathrm{hv}}}$ indicates the mean of $\sigma_{\delta_{\mathrm{hv}}}$ samples obtained in a similar manner as in step 3 but using $\delta_{\text {hv }}$ after step 4 . The value of $0.4^{\circ} \mathrm{km}^{-1}$ is found to match the $30-\mathrm{dBZ}$ level used in this work for storm cell identification.

\section{Evaluation of $K_{\mathrm{DP}}$ processing by the ZPHI method}

\section{a. Datasettings and preprocessing}

The polarimetric X-band International Research Center for Telecommunications and Radar (IRCTR) Drizzle Radar (IDRA; Figueras i Ventura 2009) is located at the Cabauw Experimental Site for Atmospheric Research (CESAR) observatory in the Netherlands (NL) at a height of $213 \mathrm{~m}$ from ground level (Leijnse et al. 2010). Its operational range and range resolution are equal to 15.3 and $0.03 \mathrm{~km}$, respectively, while the antenna rotates over $360^{\circ}$ in $1 \mathrm{~min}$. Four storm events, E1-E4, that occurred in the Netherlands during the year 2011 will be used for demonstration and analysis 
TABLE 1. Description of four storm events E1-E4 observed in the Netherlands.

\begin{tabular}{|c|c|c|c|}
\hline Event & Date & Period (UTC) & Storm type \\
\hline E1 & 18 Jun 2011 & $1200-1230$ & Single cell, area $\sim 40 \mathrm{~km}^{2}$ and range paths up to $5 \mathrm{~km}$, moderate rain \\
\hline E2 & 25 Aug 2011 & $1350-1520$ & $\begin{array}{l}\text { Mini-supercell }{ }^{\mathrm{a}} \text { with an echo appendage and } Z_{\mathrm{DR}} \text { arc, area } \sim 80 \mathrm{~km}^{2} \\
\text { and range paths up to } 10 \mathrm{~km} \text {, moderate rain }\end{array}$ \\
\hline E3 & 10 Sep 2011 & 1930-2030 & $\begin{array}{l}\text { Tornadic cell }{ }^{\mathrm{b}} \text { with a leading bow apex, area } \sim 500 \mathrm{~km}^{2} \text { and range paths } \\
\text { up to } 30 \mathrm{~km} \text {, heavy rain }\end{array}$ \\
\hline E4 & 7 Oct 2011 & $0450-0610$ & $\begin{array}{l}\text { Cells of irregular shape, area } \sim 50-100 \mathrm{~km}^{2} \text { and range paths } \sim 3-5 \mathrm{~km} \text {, } \\
\text { light rain }\end{array}$ \\
\hline
\end{tabular}

${ }^{\text {a }}$ A photograph was taken at 1454 UTC in Oudewater, $4 \mathrm{~km}$ northwest of IDRA, showing a low-topped storm with a tilted updraft structure (https://www.weerwoord.be/uploads/16820112527543.jpg by W. Kasius).

${ }^{\mathrm{b}}$ E3 resulted from an early supercell storm observed in the city of Gent, Belgium, $130 \mathrm{~km}$ southwest from an IDRA location. Radar-based vortex signatures were observed in Ameide, $4.71 \mathrm{~km}$ southeast of IDRA, where photographs of tornado damage were taken (http://www. hartvannederland.nl/top-nieuws/2011/overlast-en-schade-door-noodweer/) and reported to local news (https://www.rtlnieuws.nl/ nieuws/binnenland/gewonde-door-windhoos-bij-noodweer), indicating that E3 was a tornadic storm.

purposes. A description of these events is summarized in Table 1.

To remove areas that include particles other than rain and/or areas with low signal-to-noise ratio (SNR), measurements of linear depolarization ratio $L_{\mathrm{DR}}(\mathrm{dB})$ are used, such that range gates with $L_{\mathrm{DR}}$ larger than $-18 \mathrm{~dB}$ are discarded from $\Psi_{\mathrm{DP}}, z$, and $z_{\mathrm{dr}}$ fields. Further preprocessing includes suppressing isolated segments of a $\Psi_{\mathrm{DP}}$ profile smaller than $0.25 \mathrm{~km}$ and rejecting a $\Psi_{\mathrm{DP}}$ profile if the percentage of gates with measurements is less than $5 \%$. Because a $\Psi_{\mathrm{DP}}$ profile could be noisy at ranges behind strong reflectivity echoes associated with low SNR and fully attenuated signals, its range extent needs to be determined. The ending range of a $\Psi_{\mathrm{DP}}$ profile is determined based on $\bar{\sigma}_{P}$, which represents the average of multiple $\sigma_{P}$ samples by running a five-gate window along the $\Psi_{\mathrm{DP}}$ profile. If $\bar{\sigma}_{P}$ is less than $1.5^{\circ}$, then the ending range is given by the last measured gate in the downrange direction. Otherwise, the ending range is set by the middle gate of the second consecutive window whose $\sigma_{P}$ values are less than $\bar{\sigma}_{P}$, starting at the last measured gate and moving toward the radar. The ending range is used to limit the corresponding extent of $z$ and $z_{\mathrm{dr}}$ profiles. After this, $\bar{\sigma}_{P}$ is calculated again to estimate $K_{\mathrm{DP}}$ by the conventional technique.

\section{b. Comparison between $K_{\mathrm{DP}}$ and $A$}

Next, $K_{\mathrm{DP}}(\mathrm{C})$ and $K_{\mathrm{DP}}(\mathrm{AHR})$ will be compared against $A(\mathrm{ZPHI})$ using the empirical relation $A=$ $\alpha K_{\mathrm{DP}}$, where $\alpha$ is $0.34 \mathrm{~dB}\left({ }^{\circ}\right)^{-1}$, as suggested by Otto and Russchenberg (2011). In this scheme, $A$ (ZPHI) is used as a reference to evaluate both $K_{\mathrm{DP}}$ techniques and their impact on $Z$.

To estimate $K_{\mathrm{DP}}(\mathrm{C})$, a finite impulse response (FIR) filter is used such that the order of the filter is 36 and the cutoff range scale is $1 \mathrm{~km}$, including a Hann window.
The required threshold $\tau$ is set to $1.5 \bar{\sigma}_{P}$. Such a filter design is found suitable for $\Delta r=0.03 \mathrm{~km}$. For the estimation of $K_{\mathrm{DP}}(\mathrm{AHR})$, values of $L$ on the order of $3 \mathrm{~km}$ are associated with theoretical values of $\sigma_{K}<$ $0.5^{\circ} \mathrm{km}^{-1}$ for $\Delta r=0.03 \mathrm{~km}$ (Reinoso-Rondinel et al. 2018) and therefore $\left[L_{\min } ; L_{\max }\right]$ is predefined as $[2 ; 5] \mathrm{km}$. The $z$ and $z_{\mathrm{dr}}$ inputs are corrected for attenuation and differential attenuation, respectively, according to the DP method, in which a linear regression fit of $1 \mathrm{~km}$ is applied to $\Psi_{\mathrm{DP}}$ profiles. To estimate $\sigma_{Z_{\mathrm{DR}}}$ a five-gate window is run along a given $Z_{\mathrm{DR}}$ profile. For the calculation of $A(\mathrm{ZPHI}), \Delta \Phi_{\mathrm{DP}}$ is derived from $\Phi_{\mathrm{DP}}(\mathrm{C})$ instead of $\Phi_{\mathrm{DP}}(\mathrm{AHR})$ to evaluate $K_{\mathrm{DP}}(\mathrm{AHR})$ in an independent manner. A path interval $\left[r_{p} ; r_{q}\right]$ is defined by the first and last data points, in the downrange direction, of a $\Phi_{\mathrm{DP}}(\mathrm{C})$ profile. In cases where $\Delta \Phi_{\mathrm{DP}}<0^{\circ}$ as a result of a reduced SNR profile, the estimation of $A(\mathrm{ZPHI})$ is avoided.

Results from the storm event E1 at 1216 UTC are shown in Fig. 3. The $\Psi_{\mathrm{DP}}$ field shows a rapid increment in range on the north side of the storm, whereas $\Psi_{\mathrm{DP}}$ rarely increases on the south side. Note that the $\Psi_{\mathrm{DP}}$ field is not adjusted for phase offset. The attenuated $z$ field represents a relatively small cell of a nonuniform structure in close proximity to the radar. The $30-\mathrm{dB} Z$ contour is obtained from the attenuation-corrected $Z$ using the ZPHI method [i.e., after calculating $A(\mathrm{ZPHI})$ as explained previously]. Comparing $K_{\mathrm{DP}}(\mathrm{C})$ and $K_{\mathrm{DP}}(\mathrm{AHR})$, the $K_{\mathrm{DP}}(\mathrm{AHR})$ field is able to maintain the spatial variability of the storm down to range resolution scale, eliminating areas of $K_{\mathrm{DP}}$ smaller than $-1^{\circ} \mathrm{km}^{-1}$, which are present in $K_{\mathrm{DP}}(\mathrm{C})$. However, the coverage of the $K_{\mathrm{DP}}(\mathrm{AHR})$ field is smaller than that of $K_{\mathrm{DP}}(\mathrm{C})$. This is because in the AHR approach, it is not always possible to obtain $\Delta \Psi_{\mathrm{DP}}$ samples with negligible $\Delta \delta_{\mathrm{hv}}$; that is, $M=0$ in Eq. (2). Note that isolated $K_{\mathrm{DP}}$ segments smaller than $2 \mathrm{~km}$ were removed from both $K_{\mathrm{DP}}$ fields in 

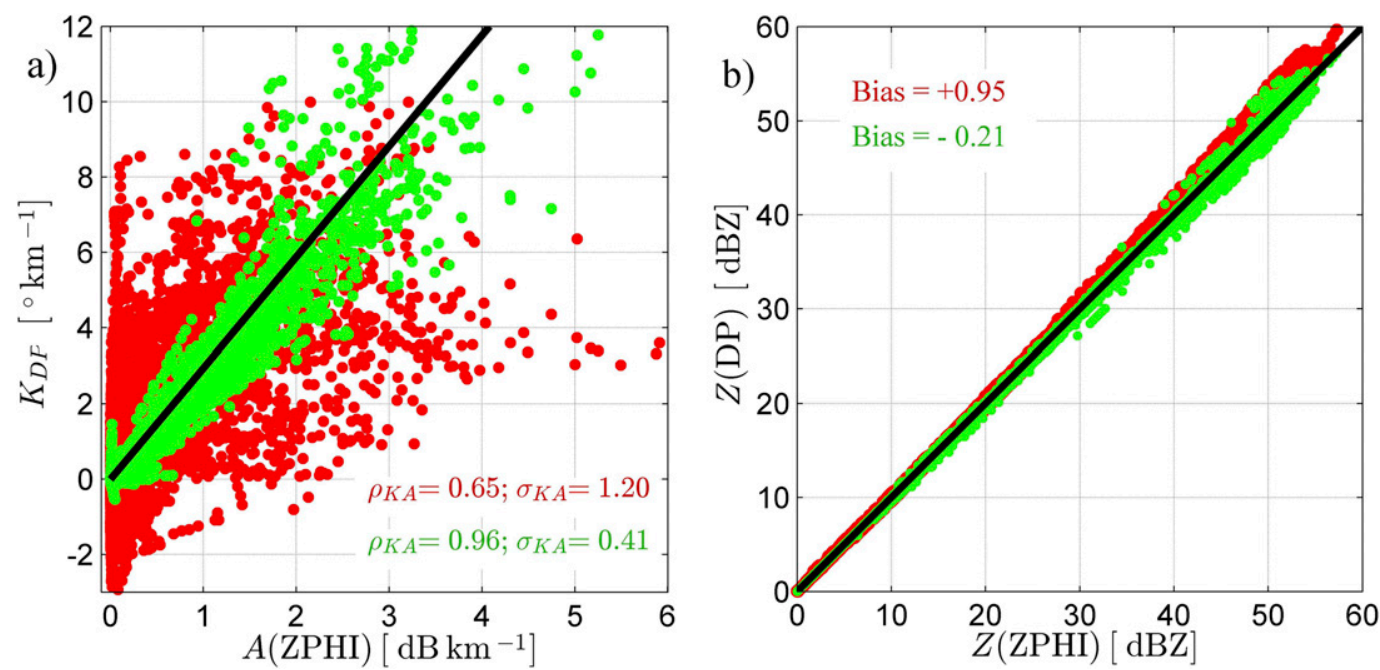

FIG. 4. (a) The $K_{\mathrm{DP}}(\mathrm{C})-A(\mathrm{ZPHI})$ scatterplot resulting from event $\mathrm{E} 1$ at $1216 \mathrm{UTC}$ is indicated by red dots, and the $K_{\mathrm{DP}}(\mathrm{AHR})-A(\mathrm{ZPHI})$ scatterplot is indicated by green dots. In addition, the empirical relation $K_{\mathrm{DP}}=(1 / \alpha) A$ is indicated by the black line, where $\alpha=0.34 \mathrm{~dB}\left({ }^{\circ}\right)^{-1}$. (b) As in (a), but for $Z(\mathrm{DP}, \mathrm{C})-Z(\mathrm{ZPHI})$ and $Z(\mathrm{DP}, \mathrm{AHR})-$ $Z(\mathrm{ZPHI})$ scatterplots. Also, the relation $Z(\mathrm{DP})=Z(\mathrm{ZPHI})$ is indicated by the black line. The biases are computed for $Z(\mathrm{ZPHI}) \geq 35 \mathrm{dBZ}$.

order to avoid estimates of $K_{\mathrm{DP}}$ that could be associated with noisy areas and/or low accuracy.

The scatterplots $K_{\mathrm{DP}}(\mathrm{C})-A(\mathrm{ZPHI})$ and $K_{\mathrm{DP}}(\mathrm{AHR})-$ $A(\mathrm{ZPHI})$ resulting from the same event, $\mathrm{E} 1$, are compared in Fig. 4. In Fig. 4a, it can be seen that the $K_{\mathrm{DP}}(\mathrm{AHR})-A(\mathrm{ZPHI})$ scatterplot (14783 data points) is more consistent than that of $K_{\mathrm{DP}}(\mathrm{C})-A(\mathrm{ZPHI})(15490$ data points) with respect to the empirical relation $A=$ $0.34 K_{\mathrm{DP}}$. In a quantified comparison, the correlation coefficient $\rho_{\mathrm{KA}}$ between $K_{\mathrm{DP}}(\mathrm{C})$ and $A(\mathrm{ZPHI})$ is equal to 0.65 , whereas for $K_{\mathrm{DP}}(\mathrm{AHR})$ and $A(\mathrm{ZPHI})$ it is 0.96 . Their corresponding standard deviations $\sigma_{\mathrm{KA}}$ with respect to the empirical relation are 1.20 and $0.41^{\circ} \mathrm{km}^{-1}$, respectively. To compare the impact of both $K_{\mathrm{DP}}$ techniques on the DP method, $z$ values are corrected for attenuation using the DP and ZPHI correction methods, and are denoted as $Z(\mathrm{DP}, \mathrm{C}), Z(\mathrm{DP}, \mathrm{AHR})$, and $Z(Z P H I, C)$; see Fig. 1 . The scatterplots $Z(D P, C)-$ $Z(\mathrm{ZPHI}, \mathrm{C})$ and $Z(\mathrm{DP}, \mathrm{AHR})-Z(\mathrm{ZPHI}, \mathrm{C})$ are compared in Fig. $4 \mathrm{~b}$ such that $Z(\mathrm{ZPHI}, \mathrm{C})$ estimates are used as reference. It is observed that for relatively high values of $Z$ (ZPHI, C), $Z$ (DP, C) values are slightly overcorrected, which agrees with Gorgucci and Chandrasekar (2005) and Snyder et al. (2010). In contrast, $Z$ (DP,AHR) values are found significantly consistent with $Z(Z P H I, C)$ estimates. The mean biases associated with $Z(D P, C)$ and $Z(\mathrm{DP}, \mathrm{AHR})$ are equal to 0.95 and $-0.21 \mathrm{~dB}$, respectively, for $Z$ (ZPHI, C) $\geq 35 \mathrm{dBZ}$. The errors quantified by $\rho_{\mathrm{KA}}, \sigma_{\mathrm{KA}}$, and bias $Z$ are summarized in Table 2 . The remaining events, E2-E4, at 1450, 1955, and 0558 UTC, respectively, were also analyzed in a similar manner and the corresponding quantified errors are indicated in Table 2.

From the previous analysis, the following can be highlighted. The values of $K_{\mathrm{DP}}(\mathrm{AHR})$ and $A(\mathrm{ZPHI})$, determined by two independent methods, show a strong agreement to the empirical relation $A=\alpha K_{\mathrm{DP}}$, leading to equivalent $Z(\mathrm{DP}, \mathrm{AHR})$ and $Z(\mathrm{ZPHI}, \mathrm{C})$ results. In the contrary, the agreement between $K_{\mathrm{DP}}(\mathrm{C})$ and $A(\mathrm{ZPHI})$ is less evident, and although $K_{\mathrm{DP}}(\mathrm{C})$ barely

TABLE 2. Comparison results between $K_{\mathrm{DP}}(\mathrm{C})$ estimates and $K_{\mathrm{DP}}(\mathrm{AHR})$ using as a reference values of $A(\mathrm{ZPHI})$ resulting from the ZPHI method for four storm events. Data points in each event are given: event E1 ( 14 000), E2 ( 13 000), E3 ( 40 000), and E4 $(\sim 30000)$.

\begin{tabular}{|c|c|c|c|c|c|c|}
\hline \multirow[b]{2}{*}{ Events } & \multicolumn{2}{|c|}{$\rho_{\mathrm{KA}}(-)$} & \multicolumn{2}{|c|}{$\sigma_{\mathrm{KA}}\left({ }^{\circ} \mathrm{km}^{-1}\right)$} & \multicolumn{2}{|c|}{ Bias $Z(\mathrm{~dB})$} \\
\hline & $K_{\mathrm{DP}}(\mathrm{C})$ & $K_{\mathrm{DP}}(\mathrm{AHR})$ & $K_{\mathrm{DP}}(\mathrm{C})$ & $K_{\mathrm{DP}}(\mathrm{AHR})$ & $K_{\mathrm{DP}}(\mathrm{C})$ & $K_{\mathrm{DP}}(\mathrm{AHR})$ \\
\hline E1 & 0.65 & 0.96 & 1.20 & 0.41 & 0.95 & -0.21 \\
\hline $\mathrm{E} 2$ & 0.48 & 0.95 & 1.75 & 0.52 & 1.05 & -0.56 \\
\hline E3 & 0.76 & 0.97 & 1.74 & 0.54 & 0.90 & -0.57 \\
\hline $\mathrm{E} 4$ & 0.59 & 0.92 & 1.15 & 0.68 & 0.98 & -0.29 \\
\hline
\end{tabular}



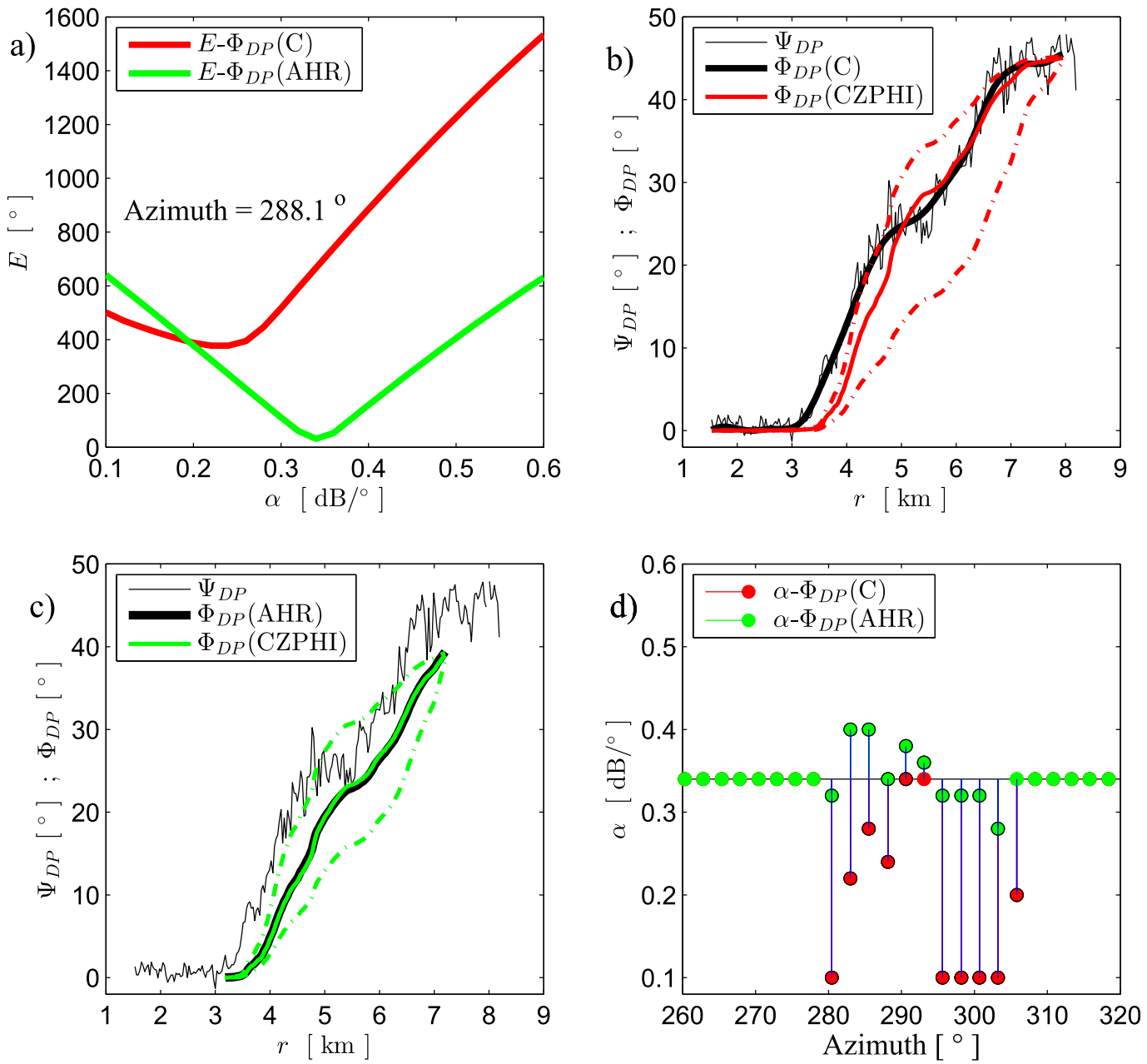

FIG. 5. (a) Errors obtained from Eq. (3): $E-\Phi_{\mathrm{DP}}(\mathrm{C})$ (red) and $E-\Phi_{\mathrm{DP}}(\mathrm{AHR})$ (green) in the azimuth $288.1^{\circ}$, as a function of $\alpha \in\left[\alpha_{\min } ; \alpha_{\max }\right]$. (b) Profiles of $\Psi_{\mathrm{DP}}, \Phi_{\mathrm{DP}}(\mathrm{C})$, and $\Phi_{\mathrm{DP}}(\mathrm{CZPHI})$ are shown as a function of range. In addition, upper and lower $\Phi_{\mathrm{DP}}(\mathrm{CZPHI})$ bounds (dashed lines) corresponding to $\alpha_{\min }$ and $\alpha_{\max }$, respectively. (c) As in (b), but using $\Phi_{\mathrm{DP}}(\mathrm{AHR})$ rather than $\Phi_{\mathrm{DP}}(\mathrm{C})$. (d) Stemplots of selected $\alpha-\Phi_{\mathrm{DP}}(\mathrm{C})(\mathrm{red})$ and $\alpha-\Phi_{\mathrm{DP}}(\mathrm{AHR})$ (green) as a function of azimuth.

includes substantial errors on attenuation-corrected $Z(\mathrm{DP}, \mathrm{C})$, it can significantly impact estimates of $A$ by the DP method. Similar findings at X-band frequencies were reported by Gorgucci and Chandrasekar (2005) but using simulated data.

\section{Impact of $K_{\mathrm{DP}}$ processing on the CZPHI method}

In this section, the ability to estimate $\Phi_{\mathrm{DP}}$ by both $K_{\mathrm{DP}}$ approaches is studied and their impact on the performance of finding optimal $\alpha$ values for the estimation of $A$ and the correction of $Z$ by the CZPHI method is measured. For analysis purposes, the minimum $E$ obtained from Eq. (3) is expressed as $E=\sum e_{i}$, with $i=$ $p, \ldots, q$, where $e_{i}$ represents the minimum error at range $r_{i}$. As such, the arithmetic mean and standard deviation of $e_{i}, \bar{e}_{\min }\left({ }^{\circ}\right)$ and $\sigma_{e_{\min }}\left({ }^{\circ}\right)$, respectively, will be used as quality measures.

At $\mathrm{X}$-band frequencies, $\left[\alpha_{\min } ; \alpha_{\max }\right]$ is predefined as $[0.1 ; 0.6] \mathrm{dB}\left({ }^{\circ}\right)^{-1}$ with steps of $0.02 \mathrm{~dB}\left(^{\circ}\right)^{-1}$, as suggested by Park et al. (2005b) and Ryzhkov et al. (2014). For a correct optimization process, it is recommended that $r_{q}-r_{p}$ should be at least $3 \mathrm{~km}$ and that $\Delta \Phi_{\mathrm{DP}}$ be larger than $10^{\circ}$. In addition, if the $\Phi_{\mathrm{DP}}(\mathrm{C})$ profile is used in Eq. (3), then the percentage of gates with $K_{\mathrm{DP}}>$ $0^{\circ} \mathrm{km}^{-1}$ should be at least $50 \%$, whereas if the $\Phi_{\mathrm{DP}}(\mathrm{AHR})$ profile is used, the percentage of gates with $K_{\mathrm{DP}}>0.5^{\circ} \mathrm{km}^{-1}$ and NSE $<20 \%$ should be larger than $80 \%$. The percentage threshold for $\Phi_{\mathrm{DP}}(\mathrm{C})$ is less than for $\Phi_{\mathrm{DP}}(\mathrm{AHR})$ because the conventional method rarely avoids negative $K_{\mathrm{DP}}$ values. If these conditions are met, $\alpha$ is selected by minimizing $E$, considering only range 

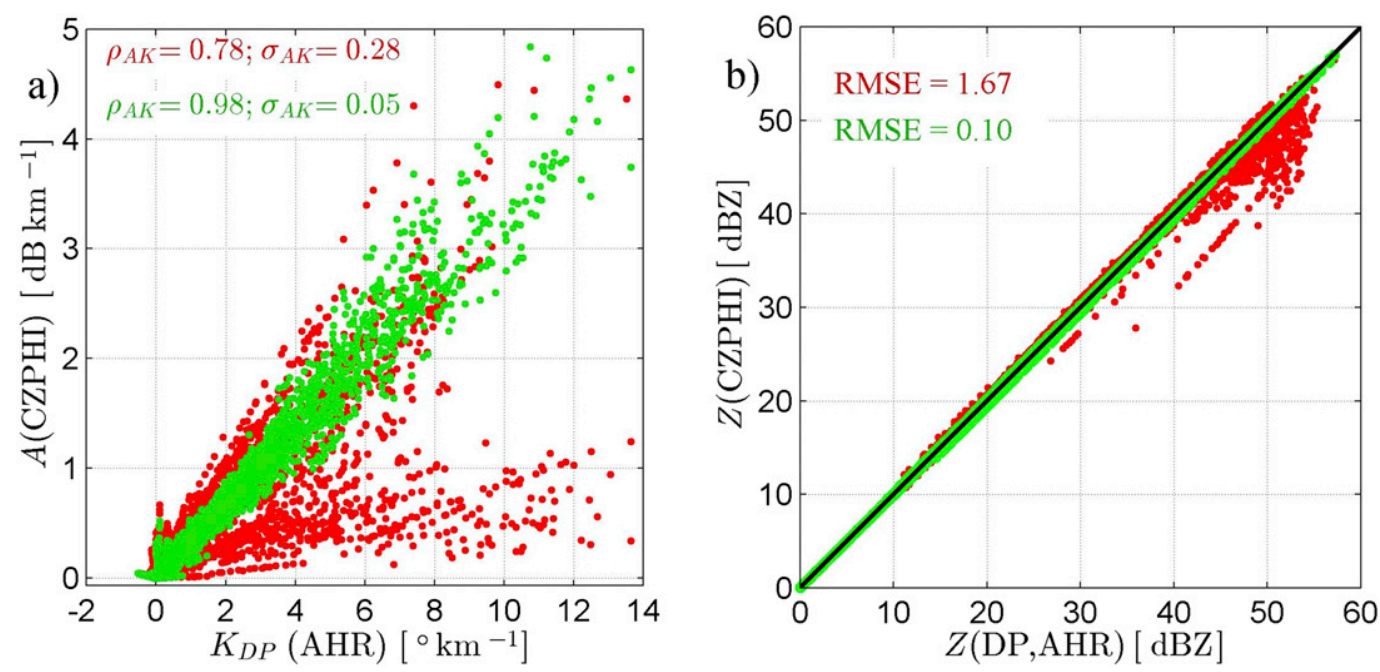

FIG. 6. (a) The $A(\mathrm{CZPHI}, \mathrm{C})-K_{\mathrm{DP}}(\mathrm{AHR})$ and $A(\mathrm{CZPHI}, \mathrm{AHR})-K_{\mathrm{DP}}(\mathrm{AHR})$ scatterplots resulting from event $\mathrm{E} 1$ at 1216 UTC are represented by the red and green dots, respectively. (b) As in (a), but for $Z(C Z P H I, C)-Z(D P, A H R)$ and $Z(\mathrm{CZPHI}, \mathrm{AHR})-Z(\mathrm{DP}, \mathrm{AHR})$ scatterplots. In addition, the relation $Z(\mathrm{CZPHI})=Z(\mathrm{DP})$ is indicated by the black line.

gates that satisfy the stated conditions; otherwise $\alpha$ is equal to $0.34 \mathrm{~dB}\left({ }^{\circ}\right)^{-1}$.

\section{a. Event E1: Single cell}

\section{1) Optimization ANALYSis}

Results involved in the optimization process along azimuth $288.1^{\circ}$ for storm event E1 at 1216 UTC are shown in Figs. 5a-c. In Fig. 5a, it is seen that the minimum $E$ when $\Phi_{\mathrm{DP}}(\mathrm{C})$ is used is much larger than when $\Phi_{\mathrm{DP}}(\mathrm{AHR})$ is used and their corresponding optimal values for $\alpha$ are $\alpha-\Phi_{\mathrm{DP}}(\mathrm{C})=0.24$ and $\alpha-\Phi_{\mathrm{DP}}(\mathrm{AHR})=$ $0.34 \mathrm{~dB}\left({ }^{\circ}\right)^{-1}$. The reason why the two $\alpha$ values are different can be explained by observing the measured $\Psi_{\mathrm{DP}}$ and the estimated $\Phi_{\mathrm{DP}}(\mathrm{C})$ and $\Phi_{\mathrm{DP}}(\mathrm{AHR})$ profiles shown in Figs. 5b and 5c, respectively. First, note that $\Psi_{\mathrm{DP}}$ might include (i) a $\delta_{\mathrm{hv}}$ bump in the range $[3.5 ; 5.5] \mathrm{km}$ and (ii) oscillations in the range $[6.5 ; 8.5] \mathrm{km}$. Second, the $\delta_{\mathrm{hv}}$ bump is more noticeable in $\Phi_{\mathrm{DP}}(\mathrm{C})$ than in $\Phi_{\mathrm{DP}}(\mathrm{AHR})$. In consequence, the matching between $\Phi_{\mathrm{DP}}(\mathrm{C})$ and $\Phi_{\mathrm{DP}}(\mathrm{CZPHI})$ shown in Fig. $5 b$ is not as good as the one observed in Fig. $5 c$. Note that $\Phi_{\mathrm{DP}}(\mathrm{CZPHI})$ represents $\Phi_{\mathrm{DP}}\left(r_{i}, \alpha\right)$ in Eq. (3). The extent of the $\Phi_{\mathrm{DP}}(\mathrm{AHR})$ profile is less than that of $\Phi_{\mathrm{DP}}(\mathrm{C})$ because $M$ in Eq. (2) appears to be 0 at the beginning and ending ranges of $\Psi_{\mathrm{DP}}$. However, this limited extent of $\Phi_{\mathrm{DP}}(\mathrm{AHR})$ avoids the oscillations seen at the ending ranges of $\Psi_{\mathrm{DP}}$.

The selected $\alpha-\Phi_{\mathrm{DP}}(\mathrm{C})$ and $\alpha-\Phi_{\mathrm{DP}}(\mathrm{AHR})$ values as a function of azimuth for the same storm are depicted in Fig. 5d. Values for $\alpha$ that are related to a minimum $E$ (i.e., optimal $\alpha$ values) are encircled by black edges, while those that are nonrelated to a minimum $E$ are represented without edges. Note that optimal $\alpha-\Phi_{\mathrm{DP}}(\mathrm{AHR})$ values are close to $0.34 \mathrm{~dB}\left({ }^{\circ}\right)^{-1}$, whereas those related to $\Phi_{\mathrm{DP}}(\mathrm{C})$ are mostly smaller than $0.34 \mathrm{~dB}\left({ }^{\circ}\right)^{-1}$ and sometime equal to $\alpha_{\min }$. An optimal $\alpha$ that equals $\alpha_{\min }$ or $\alpha_{\max }$ could be associated with an inadequate matching between the input $\Phi_{\mathrm{DP}}$ and the obtained $\Phi_{\mathrm{DP}}(\mathrm{CZPHI})$, which can lead to incorrect $\alpha$. The resulting $\bar{e}_{\min }$ values associated with $\Phi_{\mathrm{DP}}(\mathrm{C})$ and $\Phi_{\mathrm{DP}}(\mathrm{AHR})$ are $2.16^{\circ}$ and $0.20^{\circ}$, respectively, and their corresponding $\sigma_{e_{\min }}$ values are $0.75^{\circ}$ and $0.08^{\circ}$. These results come from the azimuthal sector $\left[280^{\circ} ; 310^{\circ}\right]$, which covers approximately the north side of the storm shown in Fig. 3. Outside this sector, the constant $\alpha$ was selected, associated with either $\Phi_{\mathrm{DP}}(\mathrm{C})$ or $\Phi_{\mathrm{DP}}(\mathrm{AHR})$, because the stated conditions were not met.

\section{2) Performance analysis}

The impact of the optimal selection of $\alpha-\Phi_{\mathrm{DP}}(\mathrm{C})$ and $\alpha-\Phi_{\mathrm{DP}}(\mathrm{AHR})$ on the estimation of $A(\mathrm{CZPHI})$ is measured using $K_{\mathrm{DP}}(\mathrm{AHR})$ as a reference because of 1 ) the consistency between $K_{\mathrm{DP}}(\mathrm{AHR})$ and $A(\mathrm{ZPHI})$ demonstrated in section $3 b$ and 2) the fact that the presented data were collected from one radar. Hence, the following analysis is based on internal polarimetry consistency.

The scatterplots $A(\mathrm{CZPHI}, \mathrm{C})-K_{\mathrm{DP}}(\mathrm{AHR})$ and $A(\mathrm{CZPHI}, \mathrm{AHR})-K_{\mathrm{DP}}(\mathrm{AHR})$ resulting from event $\mathrm{E} 1$ are shown in Fig. 6a. Observe that multiple $A(\mathrm{CZPHI}, \mathrm{C})$ estimates are smaller than those from $A(\mathrm{CZPHI}, \mathrm{AHR})$ as a consequence of selecting "small optimal" $\alpha-\Phi_{\mathrm{DP}}(\mathrm{C})$ values. The correlation coefficient $\rho_{\mathrm{AK}}$ from $A(\mathrm{CZPHI}, \mathrm{C})-K_{\mathrm{DP}}(\mathrm{AHR})$ is equal to 0.78 , while from $A(\mathrm{CZPHI}, \mathrm{AHR})-K_{\mathrm{DP}}(\mathrm{AHR})$ it is 0.98 . 
TABLE 3. Comparison results between $A(\mathrm{CZPHI}, \mathrm{C})$ and $A(\mathrm{CZPHI}, \mathrm{AHR})$ using $K_{\mathrm{DP}}(\mathrm{AHR})$ as a reference for four storm events.

\begin{tabular}{|c|c|c|c|c|c|c|c|c|c|c|}
\hline \multirow[b]{2}{*}{ Events } & \multicolumn{2}{|c|}{$\bar{e}_{\min }\left({ }^{\circ}\right)$} & \multicolumn{2}{|c|}{$\sigma_{e_{\min }}\left({ }^{\circ}\right)$} & \multicolumn{2}{|c|}{$\rho_{\mathrm{AK}}(-)$} & \multicolumn{2}{|c|}{$\sigma_{\mathrm{AK}}\left(\mathrm{dB} \mathrm{km}^{-1}\right)$} & \multicolumn{2}{|c|}{ RMSE $Z(\mathrm{~dB})$} \\
\hline & $\Phi_{\mathrm{DP}}(\mathrm{C})$ & $\Phi_{\mathrm{DP}}(\mathrm{AHR})$ & $\Phi_{\mathrm{DP}}(\mathrm{C})$ & $\Phi_{\mathrm{DP}}(\mathrm{AHR})$ & $\Phi_{\mathrm{DP}}(\mathrm{C})$ & $\Phi_{\mathrm{DP}}(\mathrm{AHR})$ & $\Phi_{\mathrm{DP}}(\mathrm{C})$ & $\Phi_{\mathrm{DP}}(\mathrm{AHR})$ & $\Phi_{\mathrm{DP}}(\mathrm{C})$ & $\Phi_{\mathrm{DP}}(\mathrm{AHR})$ \\
\hline E1 & 2.16 & 0.20 & 0.75 & 0.08 & 0.78 & 0.98 & 0.28 & 0.05 & 1.67 & 0.10 \\
\hline $\mathrm{E} 2$ & 2.28 & 0.27 & 0.79 & 0.25 & 0.91 & 0.97 & 0.29 & 0.11 & 1.87 & 0.32 \\
\hline E3 & 1.72 & 0.45 & 0.50 & 0.17 & 0.94 & 0.98 & 0.28 & 0.12 & 1.60 & 0.34 \\
\hline $\mathrm{E} 4$ & 2.04 & 1.25 & 1.04 & 0.89 & 0.85 & 0.89 & 0.18 & 0.07 & 1.04 & 0.17 \\
\hline
\end{tabular}

Their corresponding standard deviations $\sigma_{\mathrm{AK}}$ with respect to $A=\alpha K_{\mathrm{DP}}$ are 0.28 and $0.05 \mathrm{~dB} \mathrm{~km}^{-1}$, respectively, where $\alpha$ values are given by $\alpha-\Phi_{\mathrm{DP}}(\mathrm{AHR})$. In Fig. $6 \mathrm{~b}$, attenuation-corrected $Z(\mathrm{CZPHI}, \mathrm{C})$ and $Z(\mathrm{CZPHI}$, AHR) are compared against $Z(\mathrm{DP}, \mathrm{AHR})$, where $Z(\mathrm{DP}$, AHR) is obtained from $K_{\mathrm{DP}}(\mathrm{AHR})$ and $\alpha-\Phi_{\mathrm{DP}}(\mathrm{AHR})$. Their root-mean-square errors (RMSE) are equal to 1.67 and $0.10 \mathrm{~dB}$, respectively, for $Z(\mathrm{DP}, \mathrm{AHR}) \geq 35 \mathrm{~dB} Z$. This means that the attenuation-correctioned CZPHI method can lead to lower performance than the ZPHI method, comparing Fig. $6 \mathrm{~b}$ with Fig. 4b. In this analysis, the RMSE was used instead of the mean bias to take into account the standard deviation of $Z(\mathrm{CZPHI})$ estimates associated with the variability of $\alpha$. The quantified errors used to evaluate the CZPHI method are summarized in Table 3.

A similar analysis of $A(\mathrm{CZPHI})$ is performed using $K_{\mathrm{DP}}(\mathrm{C})$ as a reference instead of $K_{\mathrm{DP}}(\mathrm{AHR})$ and the results are summarized next. The correlation coefficient between $A(\mathrm{CZPHI}, \mathrm{C})$ and $K_{\mathrm{DP}}(\mathrm{C})$ is equal to 0.59 and smaller than those shown in Fig. 6a. This is because of the limited accuracy associated with $K_{\mathrm{DP}}(\mathrm{C})$. The resulting RMSE between $Z(\mathrm{CZPHI}, \mathrm{C})$ and $Z(\mathrm{DP}, \mathrm{C})$ is equal to 0.82 and smaller than the case when $Z(\mathrm{DP}, \mathrm{AHR})$ is used as a reference. This is because $Z(\mathrm{CZPHI}, \mathrm{C})$ and $Z(\mathrm{DP}, \mathrm{C})$ are obtained from the same $\alpha-\Phi_{\mathrm{DP}}(\mathrm{C})$ values, leading to similar attenuation correction results. Nonetheless, even if $Z(\mathrm{DP}, \mathrm{C})$ is set as a reference, their resulting RMSE is still larger than the one from $Z(\mathrm{CZPHI}, \mathrm{AHR})-Z(\mathrm{DP}, \mathrm{AHR})$.

Attenuated $z$ and $z_{\mathrm{dr}}$ and attenuation-corrected $Z$ (CZPHI, AHR) and $Z_{\mathrm{DR}}$ fields from event E1 are displayed in Fig. 7. The $Z$ (CZPHI, AHR) field restored attenuated $z$ areas with PIA values up to $14 \mathrm{~dB}$ mostly on the north side of the storm cell, which is associated with rapid increments of $\Psi_{\mathrm{DP}}$ (see Fig. 3). A similar situation is observed by comparing the fields of $z_{\mathrm{dr}}$ and $Z_{\mathrm{DR}}$, where enhanced areas of $Z_{\mathrm{DR}}$ correspond to oblate raindrops. From the $Z_{\mathrm{DR}}$ field, it seems that its lower bound is between -2 and $-1 \mathrm{~dB}$, which could be due to radar miscalibration rather than prolate-shaped particles, and therefore $Z$ and $Z_{\mathrm{DR}}$ fields may not represent calibrated measurements. Furthermore, the radial pattern presented in the $z_{\mathrm{dr}}$ and $Z_{\mathrm{DR}}$ fields may be associated with an azimuthal modulation as result of a metallic fence near the radar causing PBB effects (Giangrande and Ryzhkov 2005). Although such error sources may cause uncertainties on $Z$ and $Z_{\mathrm{DR}}$, they do not seem to affect estimates of $K_{\mathrm{DP}}$ and $A$ by neither of the discussed methods and they do not influence the results of the presented analysis.

\section{b. Event E2: Mini-supercell}

The performance of the CZPHI method from event E2 at 1450 UTC is analyzed in a similar manner as for event $\mathrm{E} 1$ and the quantified errors are summarized in Table 3. The results show again that the CZPHI method performs better when $\alpha$ is given by $\alpha-\Phi_{\mathrm{DP}}(\mathrm{AHR})$ instead of $\alpha-\Phi_{\mathrm{DP}}(\mathrm{C})$. Nonetheless, event E2 shows specific signatures associated with the spatial distribution of raindrop size that can be used to illustrate the ability of selecting proper $\alpha$ values using the outcome of both $K_{\mathrm{DP}}$ approaches.

The resulting $Z(\mathrm{CZPHI}, \mathrm{AHR})$ and $Z_{\mathrm{DR}}$ fields at 1450 UTC, associated with PIA (PIA ${ }_{D P}$ ) values up to $10 \mathrm{~dB}(1.6 \mathrm{~dB})$, are shown in Fig. 8 . In the $Z(\mathrm{CZPHI}$, AHR) field, a significant gradient can be seen along the inflow edge of the storm (arrow 1), as well as a narrow echo appendage (arrow 2). An echo appendage typically curves in the presence of a mesocyclone process; however, this feature was not seen during the considered period. The $Z_{\mathrm{DR}}$ field shows an area of significantly enhanced values along the inflow edge (arrow 3). This feature, commonly seen in supercell storms, is referred to as the $Z_{\mathrm{DR}}$ arc signature as a result of possible size sorting processes (Kumjian and Ryzhkov 2008). The fields of $K_{\mathrm{DP}}(\mathrm{C})$ and $K_{\mathrm{DP}}(\mathrm{AHR})$ are also illustrated in Fig. 8. It is seen that the $K_{\mathrm{DP}}(\mathrm{AHR})$ field retains the spatial variability of the storm better than the $K_{\mathrm{DP}}(\mathrm{C})$ field while reducing negative $K_{\mathrm{DP}}$ estimates. Note that both $K_{\mathrm{DP}}$ fields show enhanced values along the inflow edge of the storm with values as high as $12^{\circ} \mathrm{km}^{-1}$ collocated with the $Z_{\mathrm{DR}}$ arc. Estimates of $K_{\mathrm{DP}}$ over the echo appendage, in both $K_{\mathrm{DP}}$ fields, are not possible because of its narrow width of less than $1 \mathrm{~km}$.

The selected values for $\alpha-\Phi_{\mathrm{DP}}(\mathrm{C})$ and $\alpha-\Phi_{\mathrm{DP}}(\mathrm{AHR})$ are given in Fig. 9 as a function of azimuth. Observe that the optimization of $\alpha$ using $\Phi_{\mathrm{DP}}(\mathrm{C})$ was possible only in three azimuthal profiles of the mini-supercell. This is because in multiple azimuthal profiles, the 

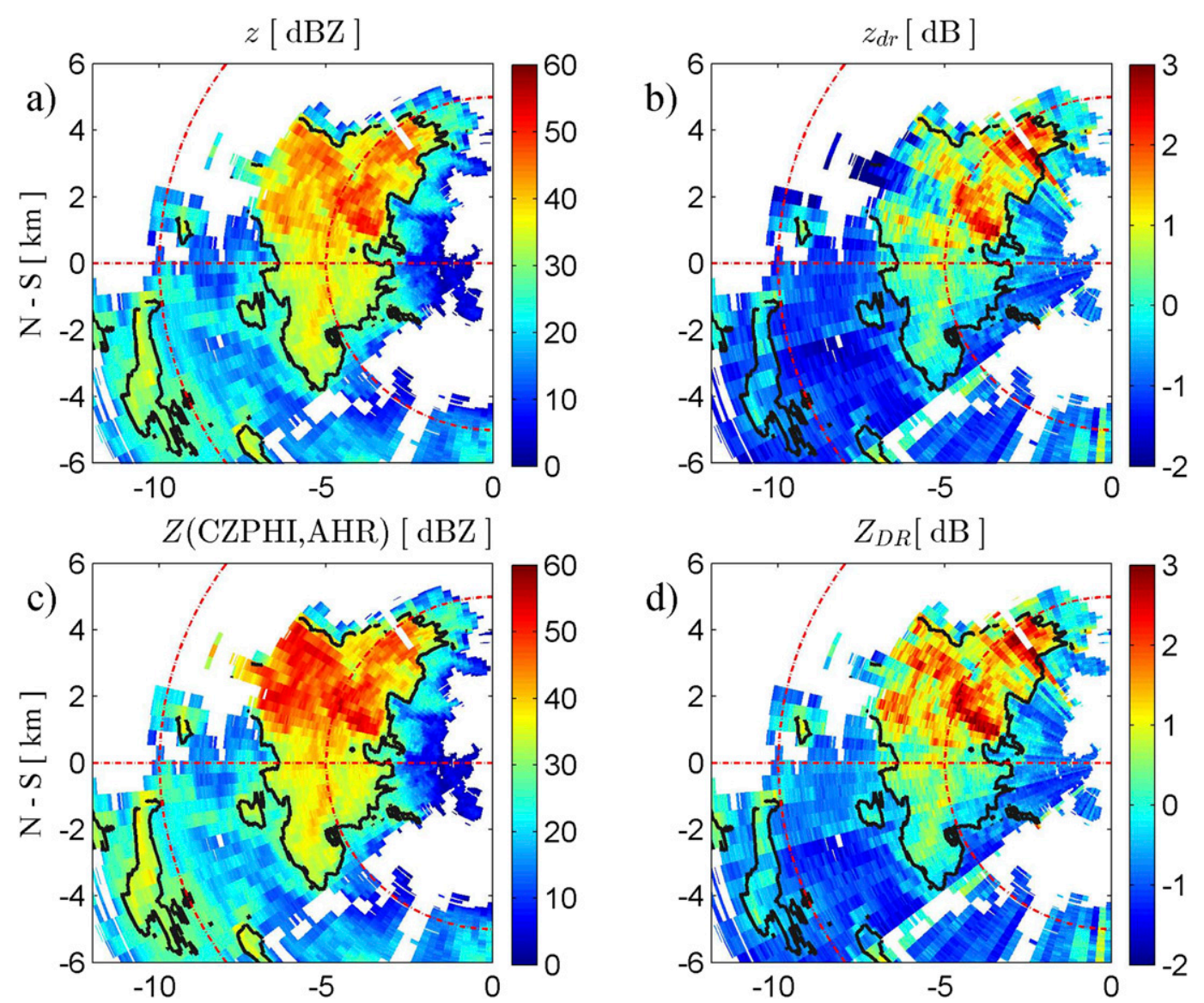

FIG. 7. Event E1 at 1216 UTC. Fields of (a) $z$, (b) $z_{\mathrm{dr}}$, (c) $Z$ (CZPHI,AHR), and (d) $Z_{\mathrm{DR}}$ are illustrated. The black contours represent the $30-\mathrm{dB} Z$ level.

percentage of gates per profile with $K_{\mathrm{DP}}(\mathrm{C})>0^{\circ} \mathrm{km}^{-1}$ is less than $50 \%$, which led to the selection of the constant $\alpha$, avoiding suboptimal $\alpha$ values. This means that in those profiles, $A$ is given by the ZPHI method, leading to a reasonable correlation $\rho_{\mathrm{AK}}$ as shown in Table 3. On the other hand, the optimization of $\alpha$ using $\Phi_{\mathrm{DP}}(\mathrm{AHR})$ occurred in multiple azimuthal profiles, resulting in values mostly larger than $0.34 \mathrm{~dB}\left({ }^{\circ}\right)^{-1}$ in contrast to those resulting from $\Phi_{\mathrm{DP}}(\mathrm{C})$. According to Ryzhkov and Zrnić (1995) and Carey et al. (2000), such large values are expected in areas of big raindrops, which is consistent with the $Z_{\mathrm{DR}}$ arc signature.

\section{c. Event E3: Tornadic cell}

This event was associated with a bow apex feature along the leading edge of the storm. According to Funk et al. (1999), cyclonic circulations can occur along or near the leading bow apex, which can produce tornadoes of F0-F3 intensity. For a detailed observation of event E3, only the southeast side of the $Z$ (CZPHI, AHR), $Z_{\mathrm{DR}}, K_{\mathrm{DP}}(\mathrm{C})$, and $K_{\mathrm{DP}}(\mathrm{AHR})$ fields at $1955 \mathrm{UTC}$ are shown in Fig. 10. The $Z$ field shows a strong gradient along the leading edge (arrow 4), indicating a region of strong convergence and low-level inflow (white arrows). A bow apex attribute resulting possibly from a descending rear inflow jet (Weisman and Trapp 2003) is also noticeable (arrow 5). This feature seems to be associated with a rotation pattern in the form of a hook or weak-echo hole (Bluestein et al. 2007) (extended arrow 6) that caused wind and tornado damage as indicated in Table 1. It is also observed that the core of the weak-echo hole, whose inner diameter is approximately $0.75 \mathrm{~km}$, is related to bounded weak $Z_{\mathrm{DR}}$ and $K_{\mathrm{DP}}$ values, located in the center of the white circles. It can be observed that $K_{\mathrm{DP}}(\mathrm{AHR})$ preserves the storm structure better than $K_{\mathrm{DP}}(\mathrm{C})$ because the AHR approach avoids a segmented $K_{\mathrm{DP}}$ texture and negative $K_{\mathrm{DP}}$ values, which are observed in the $K_{\mathrm{DP}}(\mathrm{C})$ field. Maximum values of PIA and PIA $\mathrm{DP}_{\mathrm{DP}}$ reached 18 and $3 \mathrm{~dB}$, respectively, while fully attenuated areas (south side) occurred behind strong rain echoes associated with $K_{\mathrm{DP}}$ values on the order of $10^{\circ} \mathrm{km}^{-1}$.

The resulting values of $\alpha-\Phi_{\mathrm{DP}}(\mathrm{C})$ and $\alpha-\Phi_{\mathrm{DP}}(\mathrm{AHR})$ as a function of the azimuthal sector $\left[0^{\circ} ; 360^{\circ}\right]$, not shown here, indicate that for most azimuthal profiles, 


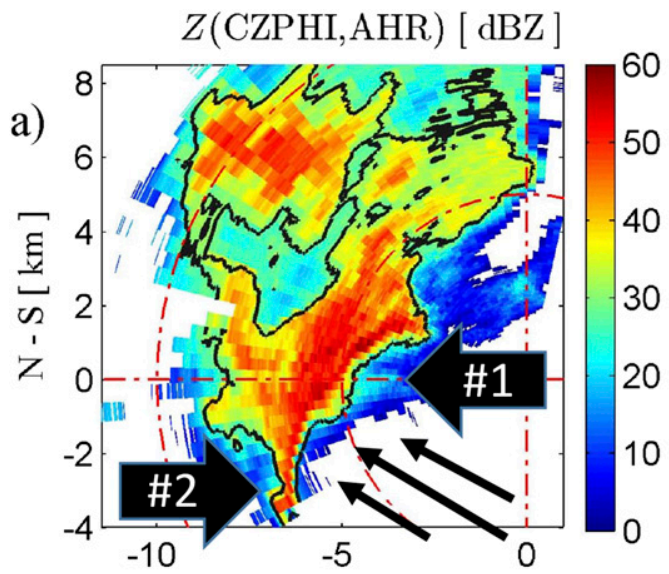

b)
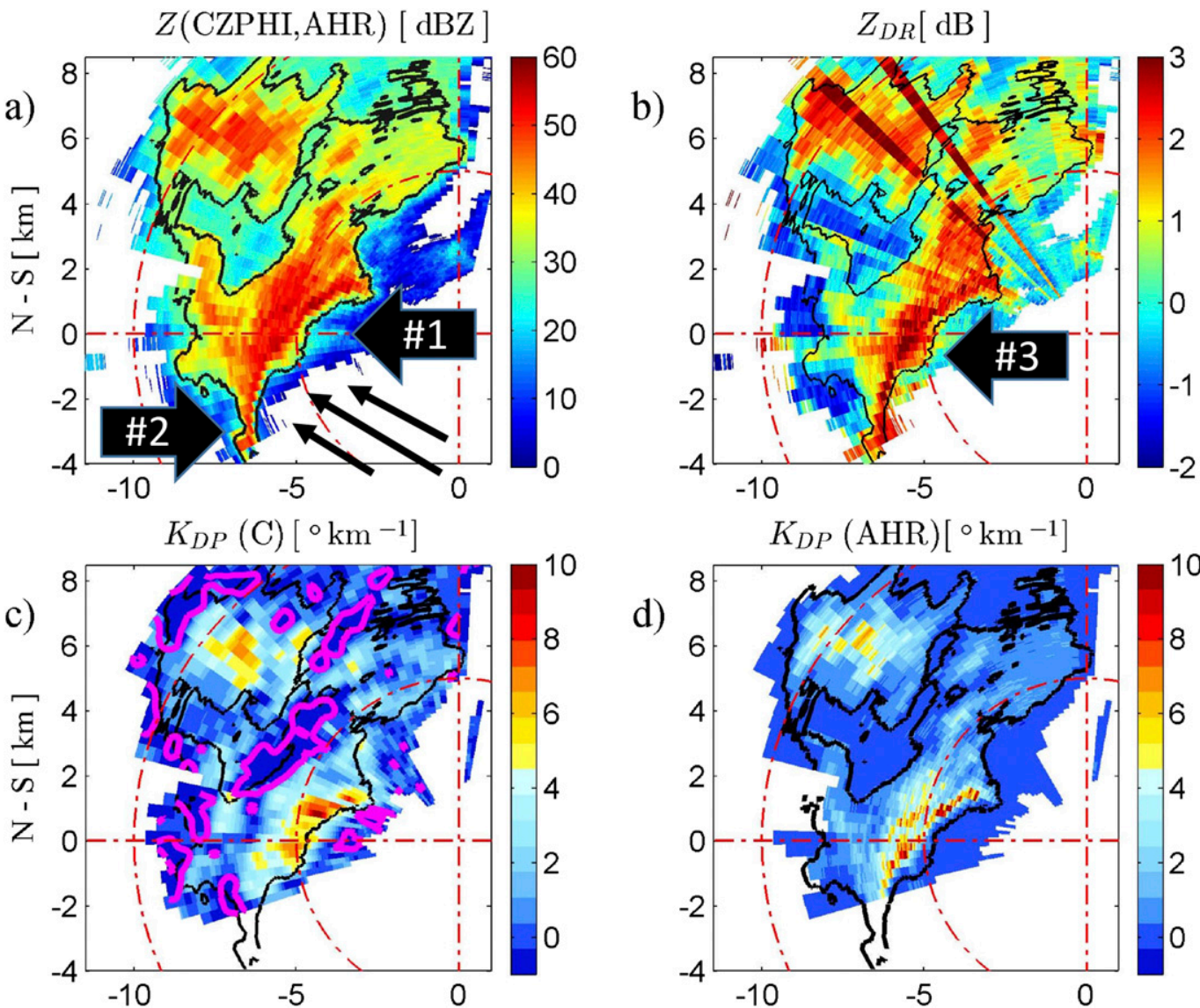

FIG. 8. Event E2 at 1450 UTC. Fields of (a) $Z(\mathrm{CZPHI}, \mathrm{AHR})$, (b) $Z_{\mathrm{DR}}$, (c) $K_{\mathrm{DP}}(\mathrm{C})$, and (d) $K_{\mathrm{DP}}$ (AHR) are shown. The black contours indicate the $30-\mathrm{dB} Z$ level, and the magenta contours in (c) show the $-1^{\circ} \mathrm{km}^{-1}$ level. In addition, the $Z$ gradient along the inflow edge, the $Z$ narrow appendage, and the $Z_{\mathrm{DR}}$ arc signatures are indicated by arrows $1-3$, respectively. The low-level inflow in (a) is represented by the three arrows.

$\alpha$ values are associated with a minimum error $E$, except in the azimuthal sector of $\left[40^{\circ} ; 120^{\circ}\right]$, where estimates of $A$ were determined by the ZPHI method. This sector was related to light and uniform rain profiles, where $\Delta \Phi_{\mathrm{DP}}$ values are smaller than $10^{\circ}$. Optimal values of $\alpha-\Phi_{\mathrm{DP}}(\mathrm{AHR})$ are predominantly found between 0.34 and $0.50 \mathrm{~dB}\left({ }^{\circ}\right)^{-1}$. The absence of $\alpha>0.50 \mathrm{~dB}\left({ }^{\circ}\right)^{-1}$, in contrast to event E2, may indicate the lack of big drops present at this time. Selected values of $\alpha-\Phi_{\mathrm{DP}}(\mathrm{C})$ are frequently smaller than or equal to $0.34 \mathrm{~dB}\left({ }^{\circ}\right)^{-1}$ but in a few profiles they are equal to 0.1 or $0.6 \mathrm{~dB}\left({ }^{\circ}\right)^{-1}$, possibly as a result of an inadequate optimization process. The resulting $\bar{e}_{\min }$ and $\sigma_{e_{\min }}$, together with $\rho_{\mathrm{AK}}, \sigma_{\mathrm{AK}}$, and RMSE are given in Table 3 , showing that $\Phi_{\mathrm{DP}}(\mathrm{AHR})$ profiles lead to more reliable values of $\alpha$ and better estimates of $A$ and $Z$.

\section{d. Event E4: Irregular-shaped cell}

In contrast to events E1-E3, E4 is mainly related to light rain with a few spots of moderate rain and it is not associated with any known reflectivity signatures. In addition, multiple radial paths with reflectivity echoes larger than $30 \mathrm{dBZ}$ are mostly smaller than $5 \mathrm{~km}$, in which PIA reached values of $2.5 \mathrm{~dB}$, and only in few profiles it increased to $14 \mathrm{~dB}$. The fields of $Z(\mathrm{CZPHI}$, AHR), $Z_{\mathrm{DR}}, K_{\mathrm{DP}}(\mathrm{C})$, and $K_{\mathrm{DP}}(\mathrm{AHR})$ at $0558 \mathrm{UTC}$ are shown in Fig. 11. Comparing the fields of $Z$ and $K_{\mathrm{DP}}$, the $K_{\mathrm{DP}}(\mathrm{AHR})$ field maintains the spatial structure of the storm better than $K_{\mathrm{DP}}(\mathrm{C})$. It can be seen that the magnitudes of $K_{\mathrm{DP}}(\mathrm{C})$ and $K_{\mathrm{DP}}(\mathrm{AHR})$ are frequently smaller than $4^{\circ} \mathrm{km}^{-1}$, implying a slow incremental behavior of estimated $\Phi_{\mathrm{DP}}$ profiles. As such, only the azimuthal sectors $\left[75^{\circ} ; 150^{\circ}\right]$ (east side) and $\left[250^{\circ} ; 280^{\circ}\right]$ (west side) were associated with $\Delta \Phi_{\mathrm{DP}}>10^{\circ}$. In both sectors, the optimization process was characterized by an inadequate performance because, in multiple azimuthal profiles, repetitive values equal to $0.1 \mathrm{~dB}$ $\left({ }^{\circ}\right)^{-1}$ were selected and the associated errors were larger than those found in E1-E3. In the remaining profiles, values of $\alpha-\Phi_{\mathrm{DP}}(\mathrm{C})$ were smaller than $0.34 \mathrm{~dB}\left({ }^{\circ}\right)^{-1}$, 


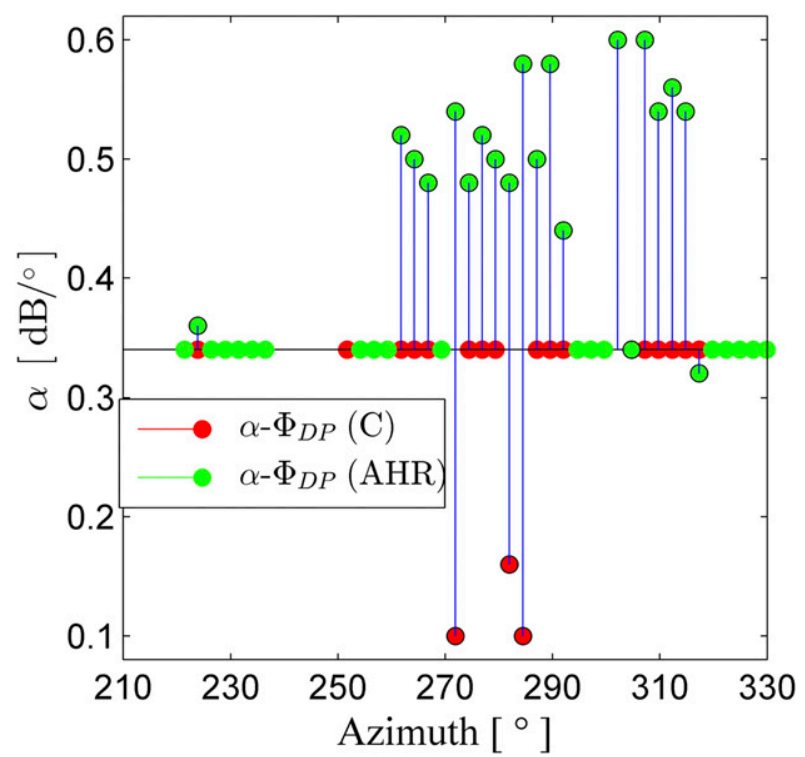

FIG. 9. Event E2 at 1450 UTC. Selected values for $\alpha$ using $\Phi_{\mathrm{DP}}(\mathrm{C})$ and $\Phi_{\mathrm{DP}}(\mathrm{AHR})$ are given by the stemplots in red and green, respectively, as a function of azimuth.

while values of $\alpha-\Phi_{\mathrm{DP}}(\mathrm{AHR})$ were comparable to $0.34 \mathrm{~dB}\left({ }^{\circ}\right)^{-1}$, indicating the absence of raindrops of considerable size. The results associated with the selection of $\alpha$ using $\Phi_{\mathrm{DP}}(\mathrm{C})$ and $\Phi_{\mathrm{DP}}(\mathrm{AHR})$ are indicated in Table 3, showing a decreased performance of the CZPHI method compared to the results of E1-E3.

\section{Evaluation of $\delta_{\mathrm{hv}}$ estimates}

For each storm event, the preprocessed $\Psi_{\mathrm{DP}}$ (section $3 \mathrm{a})$, the obtained $K_{\mathrm{DP}}(\mathrm{AHR})$ fields, and $A(\mathrm{CZPHI}$, AHR) fields were set as inputs to the $\delta_{\mathrm{hv}}$ algorithm for its evaluation. As part of the $\delta_{\text {hv }}$ approach (step 1), a low-pass FIR filter specified by a 32-filter order and $1-\mathrm{km}$ cutoff range scale was applied to the $\Psi_{\mathrm{DP}}$ field.

The estimated $\delta_{\text {hv }}$ fields resulting from storm events E1-E4 at 1216, 1450, 1955, and 0558 UTC, respectively, are shown in Fig. 12. In all events, it can be seen that the areas of $\delta_{\text {hv }}$ that are given by a uniform value correspond to the areas of $Z$ smaller than the 30-dBZ level, which defines the shape of the described storm cells. Moreover, a spatial correlation between the $\delta_{\text {hv }}$ fields and their corresponding $Z_{\mathrm{DR}}$ fields is observed, which confirms the correlation nature between $\delta_{\mathrm{hv}}$ and $Z_{\mathrm{DR}}$ (e.g., compare Figs. 12a and 7d). Such a spatial correlation is not exclusive to $\delta_{\mathrm{hv}}$ and $Z_{\mathrm{DR}}$ because a similar correlation is also observed between the fields of $\delta_{\mathrm{hv}}, Z$, and $K_{\mathrm{DP}}$, exemplifying the self-consistency relation (Scarchilli et al. 1996) between $Z_{\mathrm{DR}}, Z$, and $K_{\mathrm{DP}}$ in a comparable manner.

The ability of the algorithm to capture the spatial variability of $\delta_{\mathrm{hv}}$ is substantial. For example, in Fig. 12a, significant $\delta_{\text {hv }}$ values are more visible on the north side than on the south side of the storm cell, indicating the presence of Mie scattering. Another example of the spatial variability and consistency aspects of $\delta_{\text {hv }}$ is derived from E2, where increased $\delta_{\mathrm{hv}}$ values $\left(\delta_{\mathrm{hv}}>7^{\circ}\right)$, shown in Fig. $12 \mathrm{~b}$, are collocated with increased $Z, Z_{\mathrm{DR}}$, and $K_{\mathrm{DP}}$ values shown in Fig. 8. This scenario suggests the presence of DSDs related to big raindrops, which is consistent with the $Z_{\mathrm{DR}}$ arc shown in Fig. 8 and the large values for $\alpha$ given in Fig. 9.

In event $\mathrm{E} 3$, estimates of $\delta_{\mathrm{hv}}$ were achieved only in the azimuthal sector $\left[10^{\circ} ; 128^{\circ}\right.$, see Fig. $12 \mathrm{c}$, where it was possible to correct $\Psi_{\mathrm{DP}}^{\prime}$ profiles for system phase offset at beginning ranges (step 1). Outside this sector, $\Psi_{\mathrm{DP}}^{\prime}$ measurements were associated with a rapid increase as a result of heavy rain, not shown here, causing difficulties when removing the phase offset. Nonetheless, the $\delta_{\text {hv }}$ field shows features that are consistent with the structure of the tornadic storm, illustrated by Fig. 10, that is bounded by weak values in the center of the weak-echo hole, increased values on the south side of the apex feature, and uniform values in areas of light rain. In contrast to E3, the $\Psi_{\mathrm{DP}}^{\prime}$ field from event E4 was associated with light rain at the beginning ranges, allowing for phase-offset correction over the entire azimuthal scan. The estimated $\delta_{\mathrm{hv}}$ field shown in Fig. 12d is characterized by values in the range $2^{\circ}-5^{\circ}$, indicating that this event, in contrast to E1-E3, is dominated by small and medium raindrop sizes.

During the estimation of $\delta_{\mathrm{hv}}$, a percentage of $\delta_{\mathrm{hv}}$ samples were removed (step 3) and replaced by interpolated values (step 4). Moreover, the areas of $\delta_{\text {hv }}$ collocated with $\left|K_{\mathrm{DP}}(\mathrm{AHR})\right|<0.4^{\circ} \mathrm{km}^{-1}$ (i.e., areas of light rain) were replaced by a uniform value (step 5). The percentages $I(\%)$ of $\delta_{\mathrm{hv}}$ resulting from interpolation in E1-E4 are $25.12 \%, 27.48 \%, 29.42 \%$, and $27.06 \%$, respectively, while the uniform values $U\left(^{\circ}\right)$ are $0.59^{\circ}, 0.65^{\circ}, 0.87^{\circ}$, and $0.13^{\circ}$, respectively, and they are summarized in Table 4.

To evaluate the improvements expected from adding steps 3 and 4 to the calculation of $\delta_{\text {hv }}$ given by steps 1 and 2 [i.e., similar to the calculation derived from Eq. (1)], the results obtained from steps 1 and 2 denoted as $\delta_{\mathrm{hv}}(\mathrm{S} 12)$ and the results obtained from steps 1-4 indicated as $\delta_{\text {hv }}(\mathrm{S} 14)$ will be compared. This comparison could be performed using $Z_{\mathrm{DR}}$ measurements because $\delta_{\mathrm{hv}}$ and $Z_{\mathrm{DR}}$ show a similar sensitivity to raindrop size. However, the presented measurements of $Z_{\mathrm{DR}}$ are affected by an azimuthal modulation pattern and radar miscalibration, limiting the use of $Z_{\mathrm{DR}}$. Instead, an empirical relation in rain at $9.41 \mathrm{GHz}$ between $\delta_{\mathrm{hv}}$ and $K_{\mathrm{DP}}$ demonstrated by Schneebeli et al. (2014) is used to conduct further assessments on $\delta_{\mathrm{hv}}$. In their work, range profiles of stochastically simulated DSDs were obtained such that 

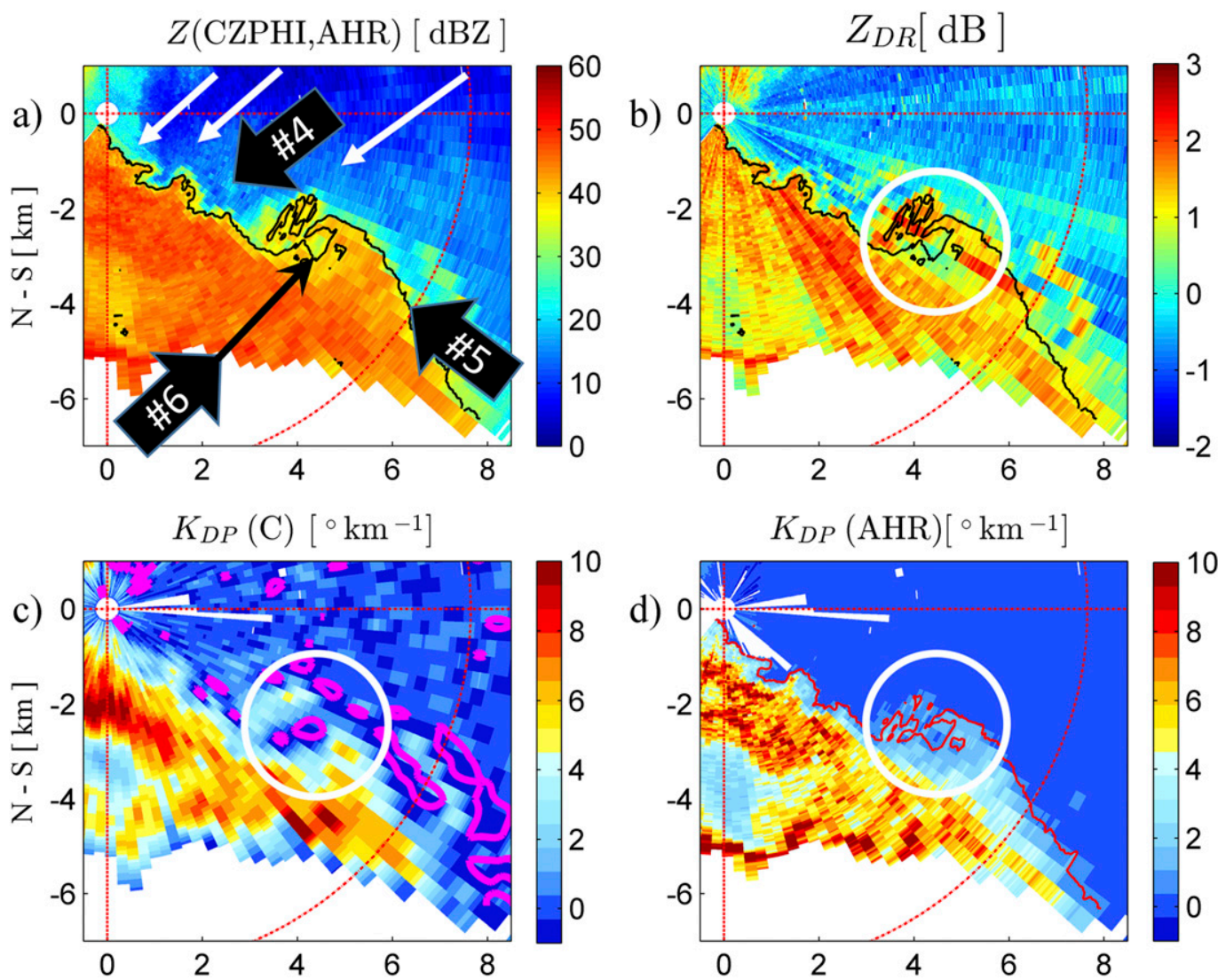

FIG. 10. Event E3 at 1955 UTC. Fields of (a) $Z(\mathrm{CZPHI}, \mathrm{AHR})$, (b) $Z_{\mathrm{DR}}$, (c) $K_{\mathrm{DP}}(\mathrm{C})$, and (d) $K_{\mathrm{DP}}(\mathrm{AHR})$ are indicated. Various levels are shown: $40 \mathrm{~dB} Z$ (black contours), $1^{\circ} \mathrm{km}^{-1}$ (red contours), and $-1^{\circ} \mathrm{km}^{-1}$ (magenta contours). The $Z$ gradient along the inflow edge (arrow 4), the bow apex (arrow 5), and the weak-echo hole (arrow 6) are given in (a). The low-level inflow (white arrows) and the rotation pattern associated with the echoweak hole (white circles) are also shown.

their DSD properties, in terms of spatial and temporal structures (i.e., small-scale variability), match the properties of DSDs measured by a network of ground-based disdrometers. Although measured DSDs could have been used instead of simulated DSDs, the simulation of representative DSDs allows for obtaining a sufficient set and a wide range of $K_{\mathrm{DP}}$ and $\delta_{\mathrm{hv}}$ values, which is rarely the case for measured DSDs. The scattering amplitudes were given by $\mathrm{T}$ matrix calculations in which three different but commonly used models for drop shape were considered, while equivolumetric spherical drop diameters were given by $[0.1 ; 7.0] \mathrm{mm}$. In addition, three temperatures of $27^{\circ}, 17^{\circ}$, and $7^{\circ} \mathrm{C}$ were included. From their simulated $\delta_{\mathrm{hv}}-K_{\mathrm{DP}}$ scatterplot (not shown here), two empirical linear fits were given as

$\mathfrak{Z}_{1}: \delta_{\mathrm{hv}}=2.37 K_{\mathrm{DP}}+0.054 \quad 0^{\circ} \leq K_{\mathrm{DP}} \leq 2.5^{\circ} \mathrm{km}^{-1}$

and

$\mathfrak{R}_{2}: \delta_{\mathrm{hv}}=0.14 K_{\mathrm{DP}}+5.5 \quad 2.5^{\circ}<K_{\mathrm{DP}} \leq 15^{\circ} \mathrm{km}^{-1}$.
The resulting $\delta_{\mathrm{hv}}(\mathrm{S} 12)-K_{\mathrm{DP}}$ and $\delta_{\mathrm{hv}}(\mathrm{S} 14)-K_{\mathrm{DP}}$ scatterplots from event E1 are presented in Fig. 13, where $K_{\mathrm{DP}}$ is given by $K_{\mathrm{DP}}(\mathrm{AHR})$. In addition, the $\bar{\delta}_{\mathrm{hv}}$ and $\bar{\delta}_{\mathrm{hv}} \pm \sigma_{\delta_{\mathrm{hv}}}$ curves, derived from $\delta_{\mathrm{hv}}(\mathrm{S} 14)$ as a function of $K_{\mathrm{DP}}$, are also shown. Both statistical curves were obtained in a similar manner as in step 3 . The strong agreement between the $\bar{\delta}_{\text {hv }}$ curve and linear fits $\Omega_{1}$ and $\Omega_{2}$ shows an indirect validation of the presented method to estimate $2 \mathrm{D} \delta_{\mathrm{hv}}$ in rain. The spread of estimated $\delta_{\mathrm{hv}}(\mathrm{S} 14)-K_{\mathrm{DP}}$ scatterplot is found to be comparable to the spread of the simulated $\delta_{\mathrm{hv}}-K_{\mathrm{DP}}$ scatterplot. Using both remarks, it can be said that the estimation of $\delta_{\mathrm{hv}}$ associated with $\delta_{\text {hv }}(\mathrm{S} 14)$ is capable of reducing the outliers seen in $\delta_{\mathrm{hv}}(\mathrm{S} 12)$, illustrating improvements from steps 3 and 4 . These outliers could be due to random oscillations of $\Psi_{\mathrm{DP}}^{\prime}$ profiles or a decreasing behavior of $\Psi_{\mathrm{DP}}^{\prime}$ with range. To quantify the consistency of the scatterplots, the mean absolute error (MAE; ${ }^{\circ}$ ) between the $\bar{\delta}_{\text {hv }}$ magnitudes and the empirical linear fits is used as a quality measure. The resulting MAE values related to 

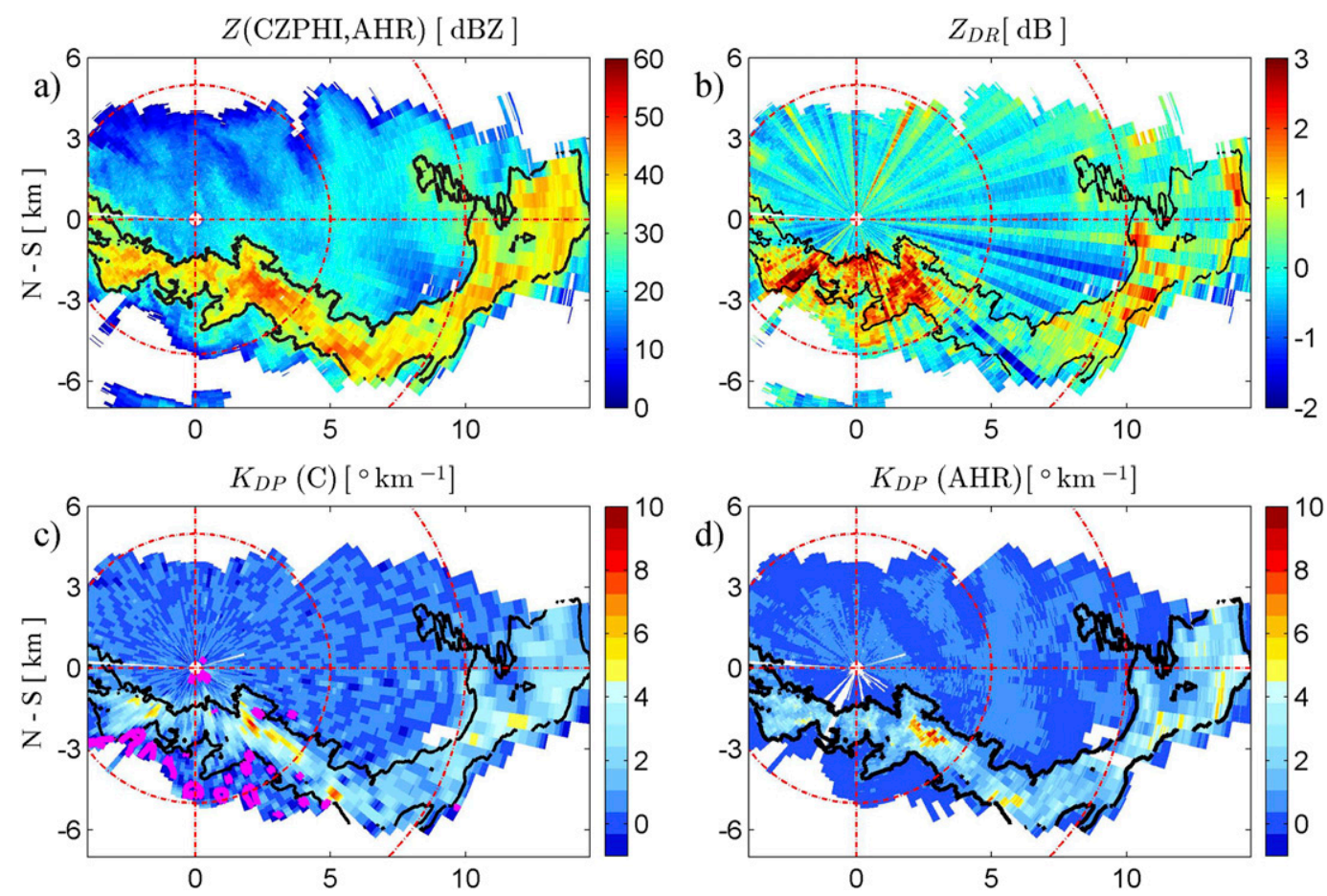

FIG. 11. As in Fig. 8, but for E4 at 0558 UTC.

$\delta_{\mathrm{hv}}(\mathrm{S} 12)$ and $\delta_{\mathrm{hv}}(\mathrm{S} 14)$ are equal to $0.74^{\circ}$ and $0.37^{\circ}$, respectively. Moreover, the arithmetic mean of the $\sigma_{\delta_{\mathrm{hv}}}$ samples [mean standard deviation $\left(\mathrm{MSD} ;{ }^{\circ}\right)$ ], derived from $\delta_{\mathrm{hv}}(\mathrm{S} 12)$ is equal to $1.66^{\circ}$, whereas for $\delta_{\mathrm{hv}}(\mathrm{S} 14)$ it is reduced to $1.10^{\circ}$. Similar analyses were conducted for events E2-E4 and the quantified errors are summarized in Table 4.

\section{Assessment on $A$ and $\delta_{\text {hv }}$ \\ a. Performance of the CZPHI method}

To further evaluate the CZPHI method, the same quality measures introduced in section 4 and the storm events E1-E4 are used but during time periods, as given in Table 1. For a representative and concise evaluation, only the results from event $\mathrm{E} 2$ will be discussed in detail. During the first $20 \mathrm{~min}$, this event consisted of an ordinary storm cell of a small size, $\sim 50 \mathrm{~km}^{2}$. When this cell was exiting the "view" of the radar, around 1420 UTC, another storm cell entered the scope of the radar. This storm manifested the characteristics of a mini-supercell during the period 1430-1500 UTC and that of a decaying storm after 1500 UTC. The quality measures resulting from event E2 are shown in Fig. 14.

Figure 14a illustrates the time series of the mean and standard deviation of the errors related to the optimization of the parameter $\alpha$. From these results, it can be inferred that the degree of similarity between the
$\Phi_{\mathrm{DP}}(\mathrm{CZPHI})$ and $\Phi_{\mathrm{DP}}$ profiles is much higher when $\Phi_{\mathrm{DP}}$ is given by $\Phi_{\mathrm{DP}}(\mathrm{AHR})$ instead of $\Phi_{\mathrm{DP}}(\mathrm{C})$, leading to a more reliable selection of $\alpha-\Phi_{\mathrm{DP}}(\mathrm{AHR})$. In the period 1415-1430 UTC, the optimization of $\alpha$ did not occur because the storm scenario was given by weak rain echoes and rain paths of less than $3 \mathrm{~km}$, which are not sufficient to meet the established conditions. The increments of $\bar{e}_{\min }$ and $\sigma_{e_{\min }}$ during 1500-1510 UTC correspond to a temporal reduction of the storm cell in size and intensity, associated with the decaying phase of the storm.

The impact of the optimization of $\alpha$ on the estimation of $A$ is quantified by comparing $A(\mathrm{CZPHI}, \mathrm{C})$ and $A(\mathrm{CZPHI}, \mathrm{AHR})$ against $K_{\mathrm{DP}}(\mathrm{AHR})$ using their degree of correlation $\rho_{\mathrm{AK}}$ and dispersion $\sigma_{\mathrm{AK}}$. The time series in Fig. 14b show values of $\rho_{\mathrm{AK}}$ very close to 1 when $A$ is given by $A(\mathrm{CZPHI}, \mathrm{AHR})$ instead of $A(\mathrm{CZPHI}, \mathrm{C})$. The two $\rho_{\mathrm{AK}}$ time series are sometimes comparable because $A$ and $K_{\mathrm{DP}}$ estimates could remain linear even if the selected values for $\alpha$ are suboptimal, provided that the $\alpha$ values are alike. In contrast, the results of $\sigma_{\mathrm{AK}}$ appear to be more sensitive to the choice of $\alpha$ because $\sigma_{\mathrm{AK}}$ evaluates the spread of the difference between $A(\mathrm{CZPHI})$ and $A(\mathrm{DP}, \mathrm{AHR})$ estimates. The decreasing behavior of $\rho_{\mathrm{AK}}$ during the period 1420-1430 UTC corresponds to inaccurate $A(\mathrm{ZPHI}, \mathrm{C})$ values resulting from noisy estimates of $\Delta \Phi_{\mathrm{DP}}$ over small paths of light rain. In Fig. 14c, the time series of RMSE illustrate the 

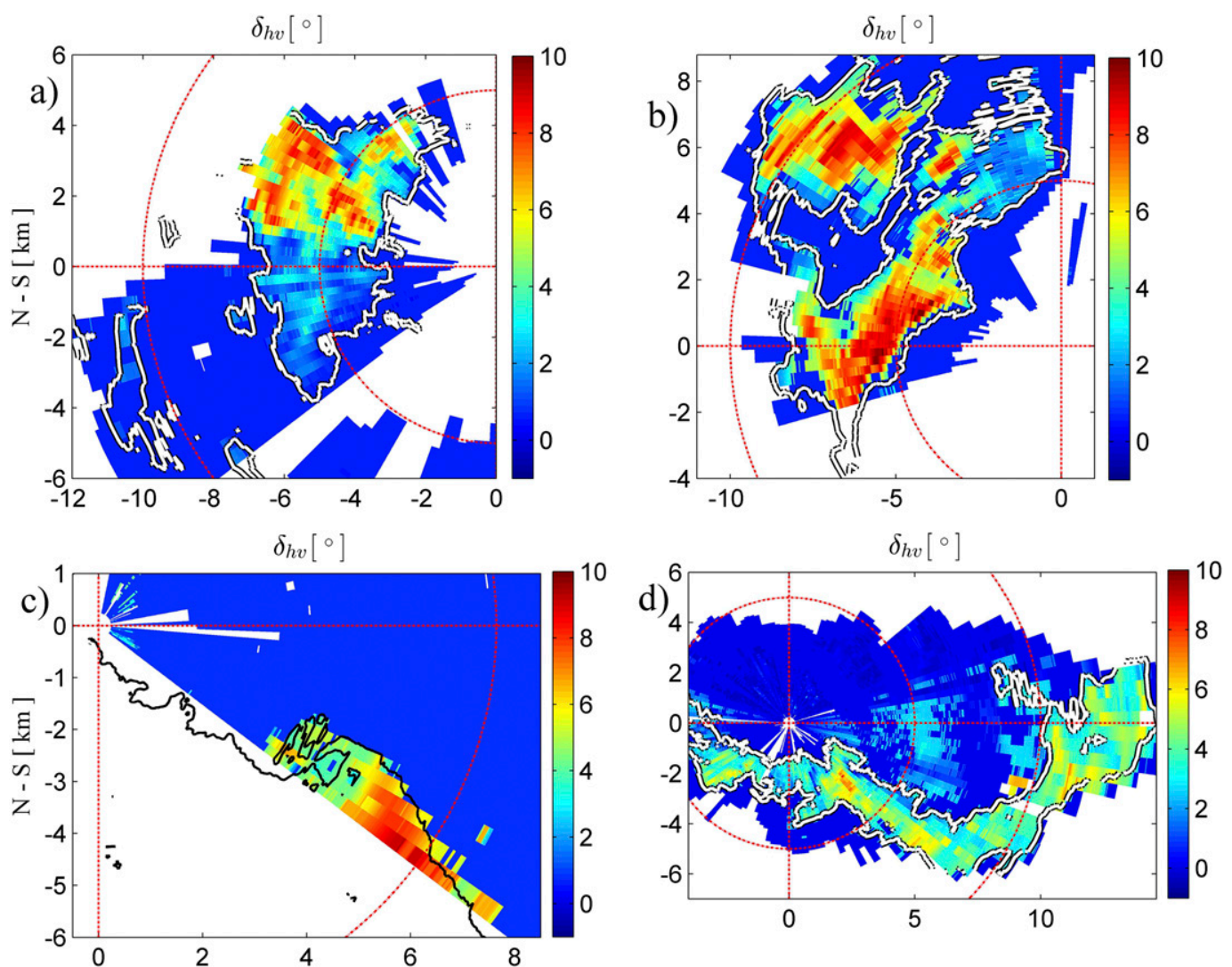

FIG. 12. The resulting fields of $\delta_{\text {hv }}$ from E1 to E4 at (a) 1216, (b) 1450, (c) 1955, and (d) 0558 UTC. The white contours indicate the $30-\mathrm{dB} Z$ level, whereas the black contours in (c) represent the $40-\mathrm{dB} Z$ level.

impact of $A(\mathrm{CZPHI})$ on attenuation-corrected $Z$. It can be said that between $A(\mathrm{CZPHI}, \mathrm{C})$ and $A(\mathrm{CZPHI}$, AHR), the estimates of $A(\mathrm{CZPHI}, \mathrm{C})$ can impact negatively on the accuracy of $Z$. Furthermore, the RMSE magnitudes for both cases tend to increase from a scenario given by an ordinary cell, before 1420 UTC, to a complex mini-supercell, after 1420 UTC. This tendency is due to the spatial structure of the storm cells that can pose a more or less challenging task to capture the sensitivity of $\alpha$ to DSD and drop size variabilities. Such a challenging level can be depicted from the $\bar{e}_{\min } \pm \sigma_{e_{\min }}$ time series, as they exhibit a noticeable spread after 1420 UTC, indicating the difficulty in minimizing the error $E$. The discontinuity of RMSE observed around 1420 UTC is because of the lack of $Z$ samples $\geq 35 \mathrm{~dB} Z$ to compute RMSE. The quality measures resulting from the events E1, E3, and E4 presented similar results to those calculated from event E2. For example, in events $\mathrm{E} 1-\mathrm{E} 4, \bar{e}_{\min }$ related to $\Phi_{\mathrm{DP}}(\mathrm{AHR})$ and $\Phi_{\mathrm{DP}}(\mathrm{C})$ were found on the order of $0^{\circ}-0.5^{\circ}$ and $1^{\circ}-2.5^{\circ}$, respectively, except in event $\mathrm{E} 4$, where it increased to $1^{\circ}$ for the case of $\Phi_{\mathrm{DP}}(\mathrm{AHR})$. In addition, RMSE values derived from $Z(\mathrm{CZPHI}, \mathrm{C})$ were found in the range of $1-2 \mathrm{~dB}$, while for $Z(\mathrm{CZPHI}, \mathrm{AHR})$ they were seen between 0 and $0.5 \mathrm{~dB}$

To analyze the distribution of the optimal values for $\alpha$ associated with a minimum $E$, the histograms of $\alpha-\Phi_{\mathrm{DP}}(\mathrm{C})$ and $\alpha-\Phi_{\mathrm{DP}}(\mathrm{AHR})$ resulting from the optimization process during the same time periods of E1-E4 are shown in Fig. 15. Each histogram consists of 11 bins whose centers are separated by $0.05 \mathrm{~dB}\left({ }^{\circ}\right)^{-1}$, while the sum of the bin heights is equal to 1 . In events E1-E3, a frequent selection of $\alpha-\Phi_{\mathrm{DP}}(\mathrm{C})$ equal to $0.1 \mathrm{~dB}\left({ }^{\circ}\right)^{-1}$ is

TABLE 4. Comparison results between $\delta_{\mathrm{hv}}$ estimates from steps 1 and 2 (S12) and steps 1-4 (S14) of the $\delta_{\mathrm{hv}}$ algorithm for four storm events. Also, the results from step 4 (S4) and step 5 (S5) are summarized. For E3, $\sim 20000$ data points were considered because of the limited sector of the $\delta_{\text {hv }}$ field.

\begin{tabular}{|c|c|c|c|c|c|c|}
\hline \multirow[b]{2}{*}{ Events } & \multicolumn{2}{|c|}{$\operatorname{MAE}\left({ }^{\circ}\right)$} & \multicolumn{2}{|c|}{$\operatorname{MSD}\left({ }^{\circ}\right)$} & \multirow{2}{*}{$\frac{I(\%)}{\mathrm{S} 4}$} & \multirow{2}{*}{$\frac{U\left(^{\circ}\right)}{\mathrm{S} 5}$} \\
\hline & $\mathrm{S} 12$ & S14 & S12 & S14 & & \\
\hline E1 & 0.74 & 0.37 & 1.66 & 1.10 & 25.12 & 0.59 \\
\hline E2 & 2.43 & 1.57 & 2.24 & 1.49 & 27.48 & 0.65 \\
\hline E3 & 2.32 & 2.04 & 1.79 & 1.37 & 29.42 & 0.87 \\
\hline E4 & 0.59 & 0.78 & 2.25 & 1.29 & 27.06 & 0.13 \\
\hline
\end{tabular}




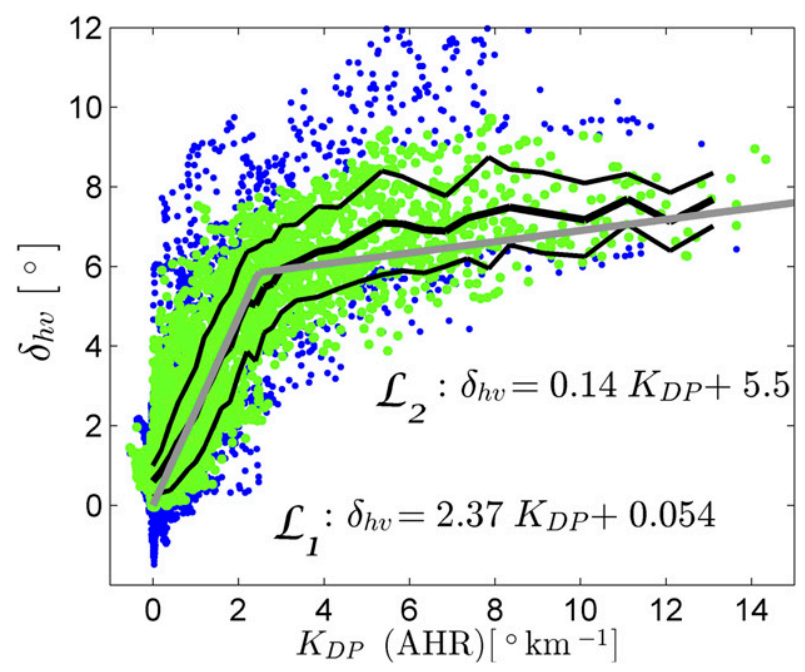

FIG. 13. Event E1 at 1216 UTC. The $\delta_{\mathrm{hv}}-K_{\mathrm{DP}}(\mathrm{AHR})$ scatterplots resulting from steps 1 and 2 (blue) and steps $1-4$ (green) of the $\delta_{\mathrm{hv}}$ algorithm. The thick black line represents $\bar{\delta}_{\text {hv }}$ (i.e., mean values of $\delta_{\text {hv }}$ estimates as a function of $K_{\mathrm{DP}}$ ), while the thin lines represent $\bar{\delta}_{\mathrm{hv}} \pm \sigma_{\delta_{\mathrm{hv}}}$. The gray straight lines indicate two linear relations, $\Omega_{1}$ and $\mathfrak{R}_{2}$, derived from scattering simulations in rain.

observed, as a result of a recurrent mismatch between the measured $\Psi_{\mathrm{DP}}$ and estimated $\Phi_{\mathrm{DP}}$, while for the case of $\alpha-\Phi_{\mathrm{DP}}(\mathrm{AHR})$ such selection is only occasionally seen. The selection of $\alpha$ in the vicinity of $0.34 \mathrm{~dB}\left({ }^{\circ}\right)^{-1}$ is more evident in the case of $\alpha-\Phi_{\mathrm{DP}}(\mathrm{AHR})$ than in the case of $\alpha-\Phi_{\mathrm{DP}}(\mathrm{C})$. This remark agrees with the empirical value of $\alpha$ that is obtained from simulations and fitting procedures. Nonetheless, the histogram of $\alpha-\Phi_{\mathrm{DP}}(\mathrm{AHR})$ from E2 also shows a reasonable contribution from $\alpha$ larger than the empirical one. The reason for such a contribution is because of the increased size of raindrops associated with the mini-supercell structure as shown in Figs. 8 and 9 and an inadequate optimization process during the decaying period. In event E4, a repetitive selection of $\alpha$ equal to 0.1 and $0.6 \mathrm{~dB}\left({ }^{\circ}\right)^{-1}$ is noted, indicating an unstable behavior of the optimization process, which agrees with the increasing behavior of the $\bar{e}_{\min }$ and $\bar{e}_{\min } \pm \sigma_{e_{\min }}$ times series but is not shown here.

\section{b. Performance of the $\delta_{\mathrm{hv}}$ algorithm}

To further assess the $\delta_{\text {hv }}$ algorithm, the results related to steps 1 and 2 and steps $1-4$ are compared using the time periods of events E1-E4 and the quality measures MAE, MSD, and $I$. Recall that MAE and MSD were calculated using the empirical relation between $\delta_{\text {hv }}$ and $K_{\mathrm{DP}}$. The time series resulting from all events are shown in Fig. 16. In general, it is observed that the results associated with $\delta_{\mathrm{hv}}(\mathrm{S} 14)$ yield more satisfying results than those from $\delta_{\mathrm{hv}}(\mathrm{S} 12)$. However, the amount
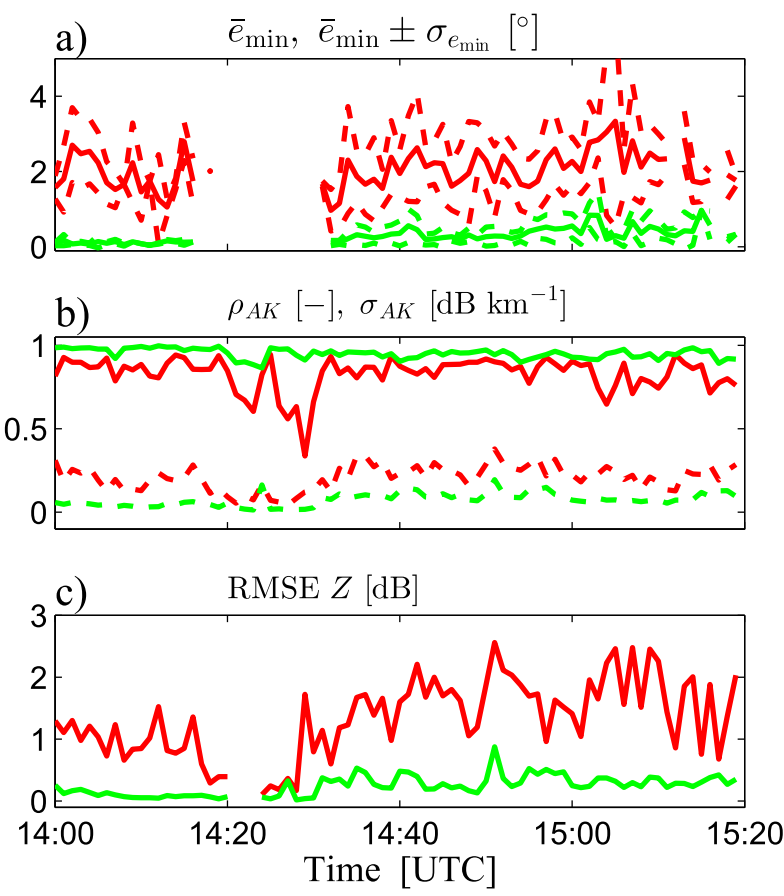

FIG. 14. Time series of quality measures from the CZPHI method for event E2. (a) Mean values $\bar{e}_{\text {min }}$ (solid lines) related to $\Phi_{\mathrm{DP}}(\mathrm{C})$ (red) and $\Phi_{\mathrm{DP}}(\mathrm{AHR})$ (green). The corresponding variabilities $\bar{e}_{\min } \pm \sigma_{e_{\min }}$ (dashed lines). (b) $\rho_{\mathrm{AK}}$ (solid lines) and $\sigma_{\mathrm{AK}}$ (dashed lines) related to $\Phi_{\mathrm{DP}}(\mathrm{C})$ (red) and $\Phi_{\mathrm{DP}}(\mathrm{AHR})$ (green). (c) RMSE of $Z$ associated with $\Phi_{\mathrm{DP}}(\mathrm{C})$ (red) and $\Phi_{\mathrm{DP}}(\mathrm{AHR})$ (green).

of improvement changes according to the evolution of the storms.

In terms of MAE, the improvement observed from $\delta_{\mathrm{hv}}(\mathrm{S} 14)$ with respect to $\delta_{\mathrm{hv}}(\mathrm{S} 12)$ is more visible during periods of light rain echoes over small paths, which complicates the estimation of $\Phi_{\mathrm{DP}}$ from noisy $\Psi_{\mathrm{DP}}$. For example, in Fig. 16a, the storm scenario of E1 during 1205-1215 UTC was dominated by segmented profiles of $\Psi_{\mathrm{DP}}$, values of $K_{\mathrm{DP}}$ in the range from $-2^{\circ}$ to $3^{\circ} \mathrm{km}^{-1}$, and a temporal increase of $\bar{e}_{\min }$. A similar scenario occurred during the last $20 \mathrm{~min}$ of event E2, Fig. 16b, that corresponds to the decaying phase of the mini-supercell storm and to the increased values of $\bar{e}_{\min }$. Note that in all events, the MAE time series resulting from $\delta_{\mathrm{hv}}(\mathrm{S} 14)$ show a different range in which they fluctuate. For instance, the resulting time series from events E1 and E3 are on the order of $0^{\circ}-1^{\circ}$, while for events E2 and E4 they are on the order of $0^{\circ}-2^{\circ}$ and $1^{\circ}-2^{\circ}$, respectively. Thus, for E1 and E3, MAE values may indicate a favorable and persistent agreement, on average, with the empirical relations. For E2 and E4, the slightly increased values of MAE reflect the challenge of estimating $\delta_{\mathrm{hv}}$, because of the strong variability of drop size, and the noisy measurements of $\Psi_{\mathrm{DP}}$, respectively. Such a range 

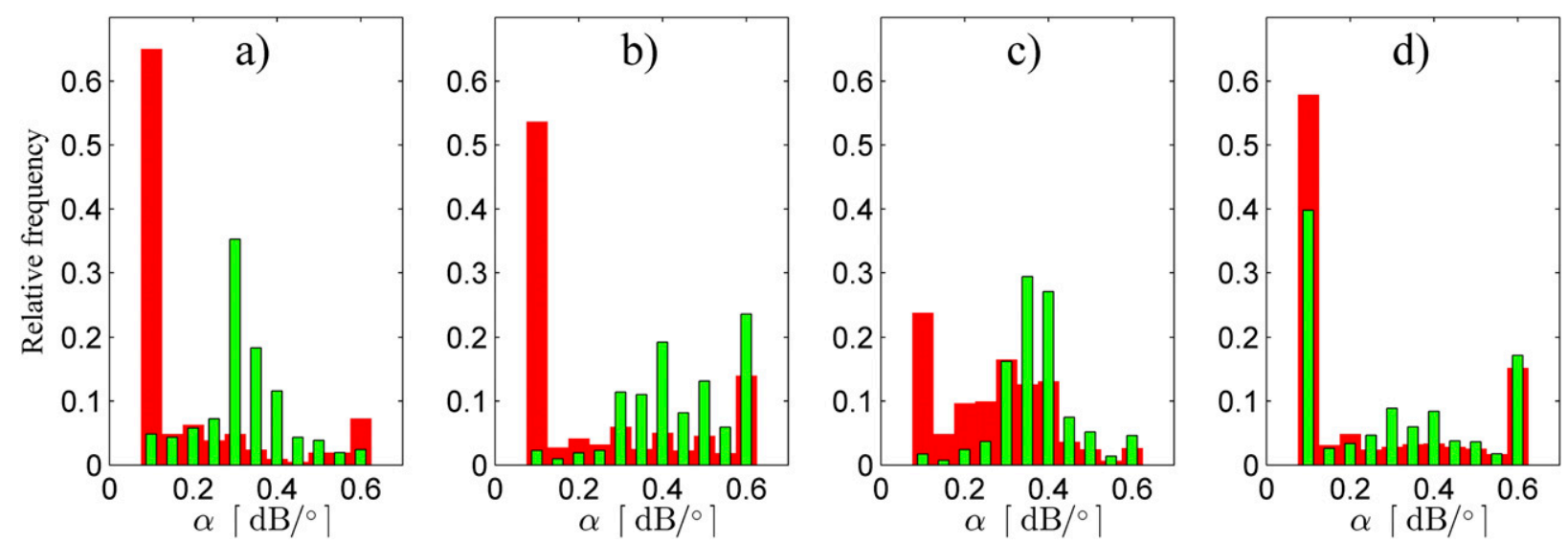

FIG. 15. (a) Histograms of optimal $\alpha-\Phi_{\mathrm{DP}}(\mathrm{C})$ (red) and $\alpha-\Phi_{\mathrm{DP}}(\mathrm{AHR})$ (green) for event E1. (b)-(d) As in (a), but for E2-E4, respectively.

of fluctuations in E2 and E4 may be linked to the accuracy of selecting optimal $\alpha$ values because the selection of suboptimal $\alpha-\Phi_{\mathrm{DP}}(\mathrm{AHR})$ values were depicted more frequently than for E1 and E3; see Fig. 15. Further, the fluctuations of MAE in all events can be connected to some extent with a misrepresentation of the empirical $\delta_{\mathrm{hv}}-K_{\mathrm{DP}}$ fit relations. The discontinuities seen in E2-E4 are associated with episodes of moderate to heavy rain located adjacent to or on top of the radar, leading to a difficult scenario to remove the offset of the $\Psi_{\mathrm{DP}}$ profiles (step 1 of the $\delta_{\text {hv }}$ method) or, sometimes, to a significant increase of the noise floor.

In contrast to MAE, MSD time series depict an evident improvement obtained from $\delta_{\mathrm{hv}}(\mathrm{S} 14)$ in relation to $\delta_{\text {hv }}(\mathrm{S} 12)$. Note that in all events, the MSD time series for the case of $\delta_{\mathrm{hv}}(\mathrm{S} 14)$ oscillate for the range of $1^{\circ}-2^{\circ}$, contrary to those observed for the range of $1^{\circ}-4^{\circ}$ for $\delta_{\mathrm{hv}}(\mathrm{S} 12)$, and show a uniform dispersion level and stable
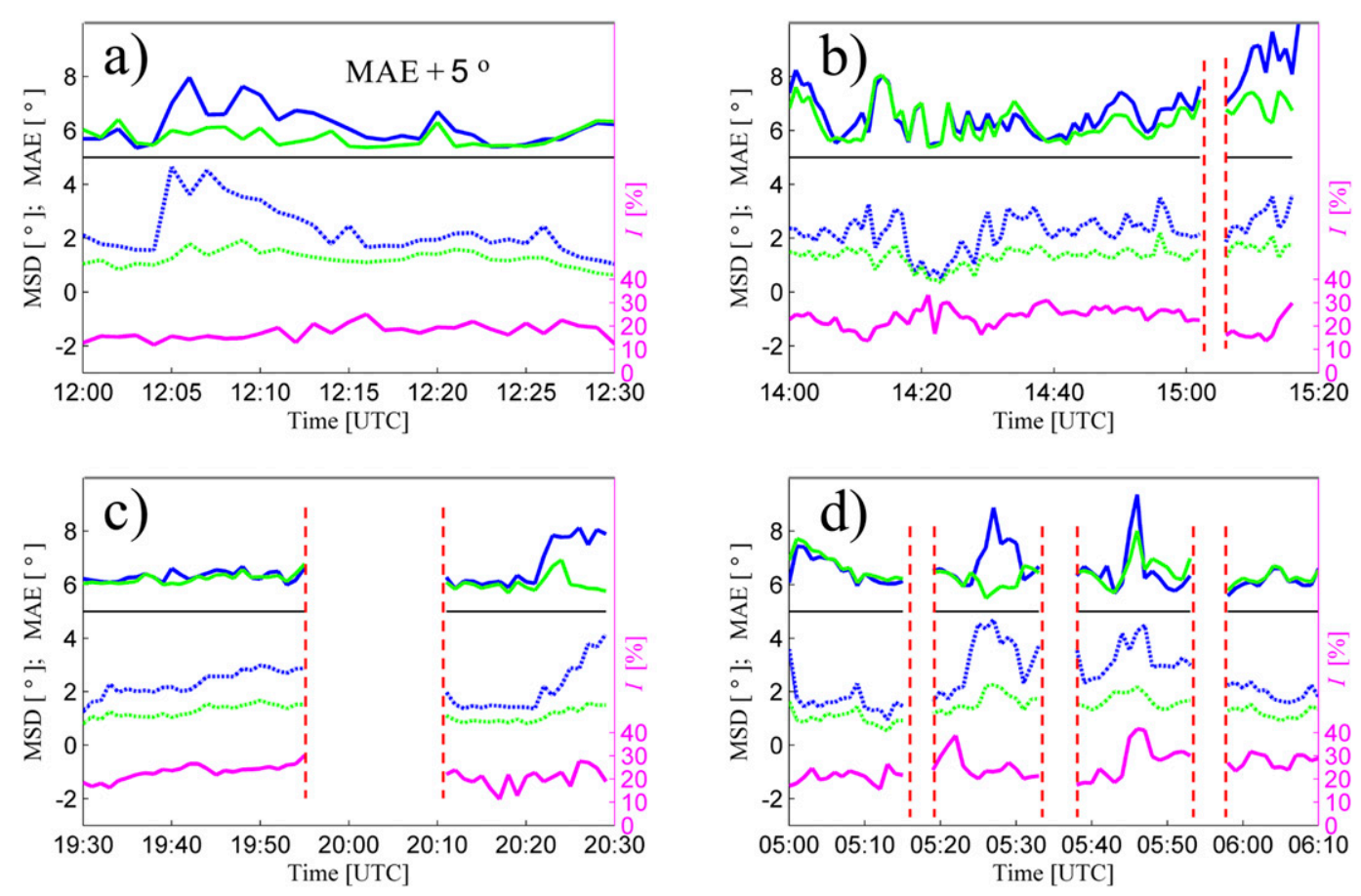

FIG. 16. (a) Time series of quality measures from the $\delta_{\text {hv }}$ algorithm for event E1. Left $y$ axis: MAE $+5^{\circ}$ resulting from steps 1 and 2 (solid blue) and from steps 1-4 (solid green). The black line indicates the $5^{\circ}$ shift. MSD from steps 1 and 2 (dashed blue) and from steps 1-4 (dashed green). Right $y$ axis: I resulting from step 4 (magenta). (b)-(d) As in (a), but for E2-E4, respectively. 
performance. The stability of the MSD values can be interpreted as a satisfactory performance of the steps 3 and 4 of the $\delta_{\mathrm{hv}}$ approach in which $\delta_{\mathrm{hv}}$ values outside the $\pm 1 \sigma_{\delta_{\mathrm{hv}}}$ extent are filtered and replaced by interpolated values. The time series of $I$ resulting from the estimation of $\delta_{\mathrm{hv}}(\mathrm{S} 14)$ represent, in a percentage manner, the number of occasions that $\delta_{\mathrm{hv}}(\mathrm{S} 12)$ estimates were replaced by interpolated values. It can be seen that the percentage of $\delta_{\text {hv }}$ samples being interpolated increases from E1 toward E4: E1 (10\%-20\%), E2 and E3 (10\%$30 \%)$, and E4 $(20 \%-40 \%)$. Such tendency is consistent with the challenging level, presented by each event, of estimating accurate $\Phi_{\mathrm{DP}}$ either from $A(\mathrm{CZPHI}, \mathrm{AHR})$ or directly from $K_{\mathrm{DP}}(\mathrm{AHR})$. Note that in this analysis, the impact of estimating $\Phi_{\mathrm{DP}}$ from $A(\mathrm{CZPHI}, \mathrm{C})$ or $K_{\mathrm{DP}}(\mathrm{C})$ on the estimation of $\delta_{\text {hv }}$ was not taken into account, instead the analysis focused on measuring the benefits of including steps 3 and 4 , which is the mitigation of erroneous $\delta_{\mathrm{hv}}$ samples derived from steps 1 and 2 .

\section{Summary and conclusions}

In weather radar polarimetry at X-band frequencies, the differential phase $\Psi_{\mathrm{DP}}$ consists of two components: the propagation differential phase $\Phi_{\mathrm{DP}}$ and the backscatter differential phase $\delta_{\mathrm{hv}}$. The use of $\Phi_{\mathrm{DP}}$-based variables such as the specific differential phase $K_{\mathrm{DP}}$ and the specific attenuation $A$ has improved radar measurements affected by, for example, attenuation, miscalibration, and partial beam blockage. Another variable of interest is $\delta_{\mathrm{hv}}$ because of its sensitivity to the dominant size of raindrops, similarly to $Z_{\mathrm{DR}}$. However, the accuracy of $K_{\mathrm{DP}}, A$, and $\delta_{\mathrm{hv}}$ strongly depends on the ability to separate $\Phi_{\mathrm{DP}}$ and $\delta_{\mathrm{hv}}$ from noisy $\Psi_{\mathrm{DP}}$ measurements, especially over short rain paths. This work has explored the impact of estimating $\Phi_{\mathrm{DP}}$ profiles on the estimation of $A$ and thereby on the attenuation correction of $Z$ using the extended version of the ZPHI method, the CZPHI method. Special attention was given to the optimization of the parameter $\alpha$ that relates $K_{\mathrm{DP}}$ and $A$ in rain. Also, a technique to improve the calculation of $\delta_{\mathrm{hv}}$ in rain has been proposed, with an emphasis on storm cells observed over short range paths. For such purposes, the conventional range-filtering method and the adaptive high-resolution (AHR) approach were implemented to estimate $K_{\mathrm{DP}}$, denoted as $K_{\mathrm{DP}}(\mathrm{C})$ and $K_{\mathrm{DP}}(\mathrm{AHR})$, respectively. Additionally, the ZPHI method (with a constant $\alpha$ ) and the CZPHI technique (with a variable $\alpha$ ) were adapted at X-band frequencies to estimate $A$, denoted as $A(\mathrm{ZPHI})$ and $A(\mathrm{CZPHI})$, respectively. Moreover, the results obtained from the AHR and CZPHI methods were included in the estimation of $\delta_{\mathrm{hv}}$ together with an interpolation process.
In the analysis associated with a constant $\alpha, K_{\mathrm{DP}}(\mathrm{AHR})$ and $A(\mathrm{ZPHI})$ magnitudes show a strong consistency, leading to a correlation coefficient of $\sim 0.96$ for moderate to heavy rain and of $\sim 0.92$ for light rain. In contrast, $K_{\mathrm{DP}}(\mathrm{C})$ and $A(\mathrm{ZPHI})$ present a low agreement; nonetheless, $K_{\mathrm{DP}}(\mathrm{C})$ and $K_{\mathrm{DP}}(\mathrm{AHR})$ lead to similar errors on the attenuation correction of $Z$, with a slight degradation related to $K_{\mathrm{DP}}(\mathrm{C})$. This means that the reduced performance of $K_{\mathrm{DP}}(\mathrm{C})$ does not severely affect the correction of $Z$, but it can negatively impact the estimation of $A$. These findings confirm the conclusions of similar studies that when $K_{\mathrm{DP}}$ (or $\Phi_{\mathrm{DP}}$ ) is not properly estimated, the performance of the DP (i.e., $A=\alpha K_{\mathrm{DP}}$ ) and $\mathrm{ZPHI}$ methods for attenuation correction purposes are similar, with a lower performance of the DP method in estimating $A$ (Gorgucci and Chandrasekar 2005).

In the study related to a variable $\alpha$, the CZPHI method was tested using $\Phi_{\mathrm{DP}}$ profiles that are given by $\Phi_{\mathrm{DP}}(\mathrm{C})$ and $\Phi_{\mathrm{DP}}(\mathrm{AHR})$. A comparative analysis indicates that in the optimization of $\alpha, \Phi_{\mathrm{DP}}(\mathrm{AHR})$ profiles lead to minimum errors smaller than those related to $\Phi_{\mathrm{DP}}(\mathrm{C})$ profiles, and therefore the $\alpha$ values associated with $\Phi_{\mathrm{DP}}(\mathrm{AHR})$ appear to better represent the variability of DSD in the observed storms. The impact of the selected values of $\alpha$ on the estimation of $A$ was measured in terms of $\rho_{\mathrm{AK}}$ and $\sigma_{\mathrm{AK}}$, showing an improved performance of the CZPHI method when $\alpha$ is associated with $\Phi_{\mathrm{DP}}(\mathrm{AHR})$ instead of $\Phi_{\mathrm{DP}}(\mathrm{C})$. A similar conclusion is given about the impact of $A(\mathrm{CZPHI})$ on the correction of $Z$ but measured in terms of the RMSE. For this analysis, $K_{\mathrm{DP}}(\mathrm{AHR})$ was used as a reference because of the strong relation seen between $K_{\mathrm{DP}}(\mathrm{AHR})$ and $A(\mathrm{ZPHI})$ and the fact that data were obtained from one radar (i.e., without independent measurements at the same time of the storm events). Nonetheless, such a methodology allows a volume-to-volume comparison between estimates of $A$ and $K_{\mathrm{DP}}$ obtained from independent approaches. On the one hand, the time series analysis illustrates the degradation of the CZPHI method when the selection of $\alpha$ is connected to $\Phi_{\mathrm{DP}}(\mathrm{C})$. This agrees with previous studies in which the performance of the CZPHI technique for attenuation correction purposes can decrease compared to the ZPHI approach (Snyder et al. 2010). On the other hand, $\Phi_{\mathrm{DP}}(\mathrm{AHR})$ seems to improve the optimal selection of $\alpha$ because the errors related to the optimization process are on the order of $0^{\circ}-0.5^{\circ}$, in contrast to $1^{\circ}-2.5^{\circ}$ for $\Phi_{\mathrm{DP}}(\mathrm{C})$. Moreover, the histograms of $\alpha-\Phi_{\mathrm{DP}}(\mathrm{AHR})$ confirm, in most of the cases, that the selection of $\alpha$ is consistent with empirical values of $\alpha$. However, in scenarios dominated by light rain, the optimization can lead to the selection of erroneous $\alpha$ values. Nonetheless, the presented analysis shows the potential of combining the 
AHR and CZPHI approaches for a better estimation of $A$ and correction of $Z$ in rain recurring to the optimization of the parameter $\alpha$ over short range paths.

The proposed $\delta_{\mathrm{hv}}$ algorithm, which considers the reconstruction of $\Phi_{\mathrm{DP}}$ by the AHR and the CZPHI approaches, provides $2 \mathrm{D} \delta_{\mathrm{hv}}$ fields that depict the spatial variability of raindrop size and exhibit a spatial distribution similar to the one of $Z_{\mathrm{DR}}$. Given that $Z$ and $K_{\mathrm{DP}}$ also depend to some extent on the size of raindrops, the estimated $\delta_{\mathrm{hv}}$ fields also show a spatial correlation with the fields of attenuation-corrected $Z$ and $K_{\mathrm{DP}}$ (AHR), mainly in areas of $K_{\mathrm{DP}}>0.4^{\circ} \mathrm{km}^{-1}$. The results of the time series analyses, which correspond to the evolution of the presented storms, show a significant agreement between estimated $\delta_{\mathrm{hv}}-K_{\mathrm{DP}}(\mathrm{AHR})$ scatterplots and experimental linear fits in rain, with a mean absolute error (MAE) and a mean standard deviation (MSD) on the order of $0^{\circ}-2^{\circ}$ and $1^{\circ}-2^{\circ}$, respectively. In addition, the time series of MAE and MSD depicted that the proposed algorithm outperformed the approach of estimating $\delta_{\mathrm{hv}}$, that is, by the difference between $\Psi_{\mathrm{DP}}$ and $\Phi_{\mathrm{DP}}$ [i.e., similar to Eq. (1)]. Such improvement is mainly because of the filtering and interpolation steps considered during the estimation of $\delta_{\mathrm{hv}}$ by the proposed algorithm. The percentage of $\delta_{\text {hv }}$ samples resulting from these two steps range from $10 \%$ to $40 \%$. This range corresponds to the amount of noise and/or fluctuations inherent to $\Psi_{\mathrm{DP}}$ and the accuracy of reconstructing $\Phi_{\mathrm{DP}}$. The suggested $\delta_{\mathrm{hv}}$ method is highly sensitive to any possible mismatch between $\Psi_{\mathrm{DP}}$ and $\Phi_{\mathrm{DP}}$ at beginning ranges. For example, $\delta_{\text {hv }}$ cannot be accurately estimated when the slope of $\Psi_{\mathrm{DP}}$ increases rapidly at beginning ranges (i.e., when a storm is on top of or adjacent to a radar). Nonetheless, the presented $\delta_{\mathrm{hv}}$ algorithm is able to depict areas of moderate to large raindrops (i.e., Mie scattering signatures) at high spatial resolution.

Even though it was shown that the presented work can provide improved estimates of $\alpha, A$, and $\delta_{\mathrm{hv}}$ in rain using data from an X-band radar with calibration limitations, further development of the proposed techniques is required to achieve the ambitions of real-time operations. This effort may require an automatic algorithm to separate rain particles from other hydrometeors, tuning of the frequency-dependent coefficients in the relations between polarimetric variables, and sensitivity analysis to temperature conditions. It may also require quality control to examine the impact of long-range observations and complex terrain-related to nonuniform beam filling, beam blockage, and phase folding —on the measurements of $\Psi_{\mathrm{DP}}, Z$, and $Z_{\mathrm{DR}}$, which can lead to a reduced performance of the discussed methods. Therefore, before applying the presented techniques, it is important to (i) identify error sources that can affect the quality of measured polarimetric variables (Gourley et al. 2006) and (ii) discriminate rain from other hydrometeors (Lim et al. 2013). In situations where $Z$ and $Z_{\mathrm{DR}}$ data are corrupted and/or in areas other than rain, it is recommended to use the conventional approach to estimate $\Phi_{\mathrm{DP}}$, the ZPHI method to estimate $A$, and the proposed algorithm to estimate $\delta_{\mathrm{hv}}$ but excluding steps 3-5. Regarding the implementation of the presented algorithms, the AHR approach is basically a mean average estimator with an adaptive but simple characteristic of the selection of the pathlengths to obtain derivatives of $\Psi_{\mathrm{DP}}$. The CZPHI method requires a $\Psi_{\mathrm{DP}}$ extent of at least $3 \mathrm{~km}$ as well as a set of predefined conditions to avoid suboptimal results. The $\delta_{\text {hv }}$ algorithm mainly adds two more steps (filtering and interpolation) to the direct estimation of $\delta_{\text {hv }}$, which do not require any costly computational processing.

A careful $\Psi_{\mathrm{DP}}$ processing is vital to unleash the full potential of polarimetric weather radars, especially at $\mathrm{X}$-band frequencies. This work shows an alternative to processing $\Psi_{\mathrm{DP}}$ profiles in rain and thereby allows an improved selection of $\alpha$ related to the CZPHI method and enhanced estimation of $\delta_{\mathrm{hv}}$ in difficult scenarios characterized by small $\Delta \Phi_{\mathrm{DP}}$ magnitudes $\left(\sim 10^{\circ}-50^{\circ}\right)$ and short path intervals $(\sim 5-10 \mathrm{~km})$. This alternative could be beneficial when a long path needs to be segmented because of detected areas of hail along a beam. Although the results of $\alpha, Z$, and $\delta_{\mathrm{hv}}$ could be further assessed using external data from, for example, a network of disdrometers, microwave links, or collocated S- and X-band radars to consolidate the findings of this work, it is foreseen that in the context of $\Psi_{\mathrm{DP}}$ processing, such as the one presented in this work, users can benefit from better observations of $\Psi_{\mathrm{DP}}$-based variables in convective storm cells.

Acknowledgments. Gratitudes to 4TUDatacentrum for its support of maintaining IDRA data, an open access dataset (Russchenberg et al. 2010). Also, the authors thank Dr. Jacopo Grazioli and Dr. Yadong Wang for their constructive discussion. This work was supported by RainGain through INTERREG IV B.

\section{REFERENCES}

Bertalmio, M., L. Vese, G. Spario, and S. Osher, 2003: Simultaneous structure and texture image inpainting. IEEE Trans. Image Process., 12, 882-889, https://doi.org/10.1109/TIP.2003.815261.

Bluestein, H., M. French, R. Tanamachi, S. Frasier, K. Hardwick, F. Junyent, and A. Pazmany, 2007: Close-range observations of tornadoes in supercells made with a dual-polarization, X-band, mobile Doppler radar. Mon. Wea. Rev., 135, 15221543, https://doi.org/10.1175/MWR3349.1.

Bringi, V. N., and V. Chandrasekar, 2001: Polarimetric Doppler Weather Radar Principles and Applications. Cambridge University Press, 636 pp. 
——, N. Balakrishman, and D. Zrnić, 1990: An examination of propagation effects in rainfall on radar measurements at microwave frequencies. J. Atmos. Oceanic Technol., 7, 829-840, https://doi.org/10.1175/1520-0426(1990)007<0829: AEOPEI $>2.0 . \mathrm{CO} ; 2$.

— T. Tennan, and V. Chandrasekar, 2001: Correcting C-band reflectivity and differential reflectivity data for rain attenuation: A self-consistent method with constraints. IEEE Trans. Geosci. Remote Sens., 39, 1906-1915, https://doi.org/10.1109/36.951081.

Carey, L., S. Rutledge, D. Ahijevych, and T. Keenan, 2000: Correcting propagation effects in C-band polarimetric radar observations of tropical convection using differential propagation phase. J. Appl. Meteor., 39, 1405-1433, https://doi.org/10.1175/ 1520-0450(2000)039<1405:CPEICB > 2.0.CO;2.

Chandrasekar, V., H. Chen, and B. Philips, 2018: Principles of highresolution radar network for hazard mitigation and disaster management in an urban environment. J. Meteor. Soc. Japan, 96A, 119-139, https://doi.org/10.2151/jmsj.2018-015.

Criminisi, A., P. Perez, and K. Toyama, 2004: Region filling and object removal by exemplar-based image inpainting. IEEE Trans. Image Process., 13, 1200-1212, https://doi.org/10.1109/ TIP.2004.833105.

D'Errico, J., 2006: Data interpolation by image inpaiting. Version 1.1.0.0, MATLAB Central File Exchange, http:// www.mathworks.com/matlabcentral/fileexchange/4551.

Diederich, M., A. Ryzhkov, C. Simmer, P. Zhang, and S. Trömel, 2015: Use of specific attenuation for rainfall measurement at X-band radar wavelengths. Part I: Radar calibration and partial beam blockage estimation. J. Hydrometeor., 16, 487502, https://doi.org/10.1175/JHM-D-14-0066.1.

Doviak, R. J., and D. S. Zrnić, 1993: Doppler Radar and Weather Observations. 2nd ed. Academic, 562 pp.

—, V. Bringi, A. Ryshkov, A. Zahrai, and D. Zrnic, 2000: Considerations for polarimetric upgrades to operational WSR-88D radars. J. Atmos. Oceanic Technol., 17, 257-278, https://doi.org/ 10.1175/1520-0426(2000)017<0257:CFPUTO>2.0.CO;2.

Elad, M., J. Starck, P. Querre, and D. Donoho, 2005: Simultaneous cartoon and texture image inpainting using morphological component analysis. Appl. Comput. Harmonic Anal., 19, 340358, https://doi.org/10.1016/j.acha.2005.03.005.

Figueras i Ventura, J., 2009: Design of a high resolution X-band Doppler polarimetric radar. Ph.D. thesis, Delft University of Technology, 162 pp.

Funk, T. W., K. E. Darmofal, J. D. Kirkpatrick, V. L. Dewald, R. W. Przybylinski, G. K. Schmocker, and Y.-J. Lin, 1999: Storm reflectivity and mesocyclone evolution associated with the 15 April 1994 squall line over Kentucky and southern Indiana. Wea. Forecasting, 14, 976-993, https://doi.org/10.1175/ 1520-0434(1999)014<0976:SRAMEA >2.0.CO;2.

Giangrande, S. E., and A. V. Ryzhkov, 2005: Calibration of dualpolarization radar in the presence of partial beam blockage. J. Atmos. Oceanic Technol., 22, 1156-1166, https://doi.org/ 10.1175/JTECH1766.1.

_ gramming to polarimetric radar differential phase processing. J. Atmos. Oceanic Technol., 30, 1716-1729, https://doi.org/ 10.1175/JTECH-D-12-00147.1.

Gorgucci, E., and V. Chandrasekar, 2005: Evaluation of attenuation correction methodology for dual-polarization radars: Application to X-band systems. J. Atmos. Oceanic Technol., 22, 1195-1206, https://doi.org/10.1175/JTECH1763.1.

,$- \ldots$, and L. Baldini, 2006: Correction of X-band radar observations for propagation effects based on the self-consistency principle. J. Atmos. Oceanic Technol., 23, 1668-1681, https:// doi.org/10.1175/JTECH1950.1.

Gourley, J. J., P. Tabary, and J. P. D. Chatelet, 2006: Data quality of the Meteo-France C-band polarimetric radar. J. Atmos. Oceanic Technol., 23, 1340-1356, https://doi.org/10.1175/ JTECH1912.1.

Grazioli, J., M. Schneebeli, and A. Berne, 2014: Accuracy of phasebased algorithm for the estimation of the specific differential phase shift using simulated polarimetric weather radar data. IEEE Geosci. Remote Sens. Lett., 11, 763-767, https://doi.org/ 10.1109/LGRS.2013.2278620.

Huang, H., G. Zhang, K. Zhao, and S. E. Giangrande, 2017: A hybrid method to estimate specific differential phase and rainfall with linear programming and physics constraints. IEEE Trans. Geosci. Remote Sens., 55, 96-111, https://doi.org/ 10.1109/TGRS.2016.2596295.

Hubbert, J., and V. N. Bringi, 1995: An iterative filtering technique for the analysis of copolar differential phase and dualfrequency radar measurements. J. Atmos. Oceanic Technol., 12, 643-648, https://doi.org/10.1175/1520-0426(1995)012<0643: AIFTFT $>2.0 . \mathrm{CO} ; 2$.

Jameson, A. R., 1992: The effect of temperature on attenuation correction schemes in rain using polarization propagation differential phase shift. J. Appl. Meteor., 31, 1106-1118, https://doi.org/ 10.1175/1520-0450(1992)031<1106:TEOTOA > 2.0.CO;2.

Kim, D.-S., M. Maki, and D.-I. Lee, 2010: Retrieval of threedimensional raindrop size distribution using X-band polarimetric radar data. J. Atmos. Oceanic Technol., 27, 1265-1285, https://doi.org/10.1175/2010JTECHA1407.1.

Kumjian, M. R., and A. V. Ryzhkov, 2008: Polarimetric signatures in supercell thunderstorms. J. Appl. Meteor. Climatol., 47, 1940-1961, https://doi.org/10.1175/2007JAMC1874.1.

Leijnse, H., and Coauthors, 2010: Precipitation measurement at CESAR, the Netherlands. J. Hydrometeor., 11, 1322-1329, https://doi.org/10.1175/2010JHM1245.1.

Lim, S., and V. Chandrasekar, 2016: A robust attenuation correction system for reflectivity and differential reflectivity in weather radars. IEEE Trans. Geosci. Remote Sens., 54, 17271737, https://doi.org/10.1109/TGRS.2015.2487984.

— , R. Cifelli, V. Chandrasekar, and S. Y. Matrosov, 2013: Precipitation classification and quantification using X-band dualpolarization weather radar: Application in the hydrometeorology testbed. J. Atmos. Oceanic Technol., 30, 2108-2120, https:// doi.org/10.1175/JTECH-D-12-00123.1.

Matrosov, S. Y., K. Clark, B. Martner, and A. Tokay, 2002: X-band polarimetric radar measurements of rainfall. J. Appl. Meteor., $\mathbf{4 1}$, 941-952, https://doi.org/10.1175/1520-0450(2002)041<0941: $\mathrm{XBPRMO}>2.0 . \mathrm{CO} ; 2$.

_ D. E. Kingsmill, B. E. Martner, and F. M. Ralph, 2005: The utility of X-band polarimetric radar for quantitative estimates of rainfall parameters. J. Hydrometeor., 6, 248-262, https:// doi.org/10.1175/JHM424.1.

_ P. C. Kennedy, and R. Cifelli, 2014: Experimentally based estimates of relations between X-band radar signal attenuation characteristics and differential phase in rain. J. Atmos. Oceanic Technol., 31, 2442-2450, https://doi.org/10.1175/ JTECH-D-13-00231.1.

McLaughlin, D., and Coauthors, 2009: Short-wavelength technology and the potential for distributed networks of small radar systems. Bull. Amer. Meteor. Soc., 90, 1797-1817, https:// doi.org/10.1175/2009BAMS2507.1.

Otto, T., and H. W. J. Russchenberg, 2010: Estimation of the raindropsize distribution at $\mathrm{X}$-band using specific differential phase and 
differential backscatter phase. Proc. Sixth European Conf. on Radar in Meteorology and Hydrology (ERAD 2010), Sibiu, Romania, Meteor Romania, 6 pp., https:/www.erad2010.com/pdf/ oral/thursday/xband/07_ERAD2010_0109.pdf.

— differential backscatter phase from polarimetric weather radar measurements of rain. IEEE Geosci. Remote Sens. Lett., $\mathbf{8}$, 988-992, https://doi.org/10.1109/LGRS.2011.2145354.

Park, S.-G., V. N. Bringi, V. Chandrasekar, M. Maki, and K. Iwanami, 2005a: Correction of radar reflectivity and differential reflectivity for rain attenuation at $\mathrm{X}$ band. Part I: Theoretical and empirical basis. J. Atmos. Oceanic Technol., 22, 1621-1632, https://doi.org/10.1175/JTECH1803.1.

_- M. Maki, K. Iwanami, V. N. Bringi, and V. Chandrasekar, 2005b: Correction of radar reflectivity and differential reflectivity for rain attenuation at $\mathrm{X}$ band. Part II: Evaluation and application. J. Atmos. Oceanic Technol., 22, 1633-1655, https://doi.org/10.1175/JTECH1804.1.

Reinoso-Rondinel, R., C. Unal, and H. Russchenberg, 2018: Adaptive and high-resolution estimation of specific differential phase for polarimetric X-band weather radars. J. Atmos. Oceanic Technol., 35, 555-573, https://doi.org/10.1175/ JTECH-D-17-0105.1.

Russchenberg, H., T. Otto, R. Reinoso-Rondinel, C. Unal, and J. Yin, 2010: IDRA weather radar measurements-All data. 4TU Centre for Research Data, Delft University of Technology. Subset used: IDRA processed data with standard range, accessed 12 October 2012, https://doi.org/10.4121/uuid: 5f3bcaa2-a456-4a66-a67b-1eec928cae6d.

Ryzhkov, A., and D. S. Zrnić, 1995: Precipitation and attenuation measurements at $10-\mathrm{cm}$ wavelength. J. Appl. Meteor., 34, 2121-2134, https://doi.org/10.1175/1520-0450(1995)034<2120: PAAMAA $>2.0 . \mathrm{CO} ; 2$.

— Comparative analysis and operational implications. 32nd Conf. on Radar Meteor., Albuquerque, NM, Amer. Meteor. Soc., 9R3, https:/ams.confex.com/ams/32Rad11Meso/webprogram/ Paper95684.html.

_ M. Diederich, P. Zhang, and C. Simmer, 2014: Potential utilization of specific attenuation for rainfall estimation, mitigation of partial beam blockage, and radar networking.
J. Atmos. Oceanic Technol., 31, 599-619, https://doi.org/ 10.1175/JTECH-D-13-00038.1.

Scarchilli, G., E. Gorgucci, V. Chandrasekar, and T. A. Seliga, 1993: Rainfall estimation using polarimetric techniques at C-band frequencies. J. Appl. Meteor., 32, 1150-1160, https://doi.org/ 10.1175/1520-0450(1993)032<1150:REUPTA > 2.0.CO;2.

,,--- , and A. Dobaie, 1996: Self-consistency of polarization diversity measurement of rainfall. IEEE Trans. Geosci. Remote Sens., 34, 22-26, https://doi.org/10.1109/36.481887.

Schneebeli, M., and A. Berne, 2012: An extended Kalman filter framework for polarimetric X-band weather radar data processing. J. Atmos. Oceanic Technol., 29, 711-730, https:// doi.org/10.1175/JTECH-D-10-05053.1.

_ J. Jrazioli, and A. Berne, 2014: Improved estimation of the specific differential phase shift using a compilation of Kalman filter ensembles. IEEE Trans. Geosci. Remote Sens., 52, 51375149, https://doi.org/10.1109/TGRS.2013.2287017.

Snyder, J., H. Bluestein, and G. Zhang, 2010: Attenuation correction and hydrometeor classification of high-resolution, $\mathrm{X}$-band, dual-polarized mobile radar measurements in severe convective storms. J. Atmos. Oceanic Technol., 27, 19792001, https://doi.org/10.1175/2010JTECHA1356.1.

Testud, J., E. L. Bouar, E. Obligis, and M. Ali-Mehenni, 2000: The rain profiling algorithm applied to polarimetric weather radar. J. Atmos. Oceanic Technol., 17, 332-356, https://doi.org/ 10.1175/1520-0426(2000)017<0332:TRPAAT>2.0.CO;2.

Trömel, S., M. R. Kumjian, A. V. Ryzhkov, C. Simmer, and M. Diederich, 2013: Backscatter differential phase-Estimation and variability. J. Appl. Meteor. Climatol., 52, 2529-2548, https://doi.org/10.1175/JAMC-D-13-0124.1.

Wang, Y., and V. Chandrasekar, 2009: Algorithm for estimation of the specific differential phase. J. Atmos. Oceanic Technol., 26, 2565-2578, https://doi.org/10.1175/2009JTECHA1358.1.

_- P. Zhang, A. V. Ryzhkov, J. Zhang, and P.-L. Chang, 2014: Utilization of specific attenuation for tropical rainfall estimation in complex terrain. J. Hydrometeor., 15, 2250-2266, https://doi.org/ 10.1175/JHM-D-14-0003.1.

Weisman, M., and R. Trapp, 2003: Low-level mesovortices within squall lines and bow echoes. Part I: Overview and dependence on environment shear. Mon. Wea. Rev., 131, 2779-2803, https:// doi.org/10.1175/1520-0493(2003)131<2779:LMWSLA>2.0.CO;2. 